ARTICLE

https://doi.org/10.1038/s41467-019-13815-w

\title{
The mechanistic and functional profile of the therapeutic anti-lgE antibody ligelizumab differs from omalizumab
}

Pascal Gasser (10 1,2,3,6, Svetlana S. Tarchevskaya 4,6, Pascal Guntern (10) 1,2,3, Daniel Brigger ${ }^{1,2}$, Rahel Ruppli ${ }^{1,2}$, Noemi Zbären ${ }^{1,2}$, Silke Kleinboelting ${ }^{4}$, Christoph Heusser ${ }^{5}$, Theodore S. Jardetzky (1) ${ }^{4,6 \star}$ \& Alexander Eggel (10) 1,2,6*

Targeting of immunoglobulin E (IgE) represents an interesting approach for the treatment of allergic disorders. A high-affinity monoclonal anti-lgE antibody, ligelizumab, has recently been developed to overcome some of the limitations associated with the clinical use of the therapeutic anti-IgE antibody, omalizumab. Here, we determine the molecular binding profile and functional modes-of-action of ligelizumab. We solve the crystal structure of ligelizumab bound to IgE, and report epitope differences between ligelizumab and omalizumab that contribute to their qualitatively distinct IgE-receptor inhibition profiles. While ligelizumab shows superior inhibition of IgE binding to FceRI, basophil activation, IgE production by B cells and passive systemic anaphylaxis in an in vivo mouse model, ligelizumab is less potent in inhibiting IgE:CD23 interactions than omalizumab. Our data thus provide a structural and mechanistic foundation for understanding the efficient suppression of FceRI-dependent allergic reactions by ligelizumab in vitro as well as in vivo.

\footnotetext{
${ }^{1}$ Department of BioMedical Research, University of Bern, Bern, Switzerland. ${ }^{2}$ Department of Rheumatology, Immunology and Allergology, University Hospital Bern, Bern, Switzerland. ${ }^{3}$ Graduate School of Cellular and Biomedical Sciences, University of Bern, Bern, Switzerland. ${ }^{4}$ Department of Structural Biology, Stanford University School of Medicine, Stanford, CA 94305, USA. ${ }^{5}$ Pharmaceutical Research, Novartis AG, 4002 Basel, Switzerland. ${ }^{6}$ These authors contributed equally: Pascal Gasser, Svetlana S. Tarchevskaya, Theodore S. Jardetzky, Alexander Eggel. *email: tjardetzky@stanford.edu; alexander. eggel@dbmr.unibe.ch
} 
A $s$ a key driver in the development and manifestation of hypersensitivity reactions against normally nonhazardous substances, immunoglobulin $\mathrm{E}$ (IgE) has become a major target of therapeutic intervention strategies ${ }^{1-3}$. $\mathrm{IgE}$ is known to interact with two major receptors, FceRI and CD23/FceRII ${ }^{4}$, which are involved in different immunological processes $^{5}$. Binding of allergen-specific IgE to FceRI expressed on immunological effector cells including basophils and mast cells occurs with high affinity $\left(K_{\mathrm{D}} 10^{-10} \mathrm{M}\right)$. This interaction occurs via two asymmetric binding sites on the receptor and is stabilized through the induction of a conformational change in $\mathrm{IgE}^{6-8}$. Exposure to allergens induces cross-linking of IgE-bound FceRI resulting in immediate activation of allergic effector cells, which culminates in cellular degranulation and the release of vasoactive and pro-inflammatory mediators ${ }^{9}$.

While this FceRI-dependent cellular degranulation process accounts for immediate hypersensitivity reactions and the induction of clinical allergy symptoms, the interaction of IgE with CD23 has been reported to be involved in antigen presentation, the transport of antigens across airway and intestinal epithelial barriers and the regulation of $\mathrm{IgE}$ synthesis ${ }^{10-13}$. Binding of $\mathrm{IgE}$ to monomeric $\mathrm{CD} 23$ is of low affinity $\left(K_{\mathrm{D}} 10^{-6}-10^{-7} \mathrm{M}\right)^{14}$. However, cell surface $\mathrm{CD} 23$ is prone to oligomerization leading to enhanced binding of IgE:allergen complexes on antigen presenting cells ${ }^{10,15}$. Furthermore, various studies have provided evidence that $\mathrm{IgE}$ binding to $\mathrm{CD} 23$ on B-cells negatively regulates $\operatorname{IgE}$ synthesis ${ }^{11,13,16}$.

Over the last decades, various anti-IgE inhibitors including antibodies $^{17-22}$, DARPin ${ }^{\circledast}$ proteins $^{23-25}$ and nanobodies ${ }^{26,27}$ have been generated and tested in pre-clinical studies. To date, the monoclonal antibody omalizumab (Xolair ${ }^{\circledR}$ ) represents the only licensed anti-IgE compound for clinical use. Omalizumab shows remarkable therapeutic efficacy in allergic asthma and chronic spontaneous urticaria ${ }^{17,28,29}$. Recently, a next-generation highaffinity anti-IgE monoclonal antibody (ligelizumab; QGE031) has been developed with the intention of overcoming some of the limitations associated with omalizumab ${ }^{18,30}$.

Given its current status as a potential anti-IgE therapeutic and successor to omalizumab, we sought to investigate the IgE binding characteristics of ligelizumab and its modes-of-action. Here, we report the crystal structure of ligelizumab bound to IgE, revealing that it recognizes a distinct IgE epitope only partially overlapping with that of omalizumab. Ligelizumab interacts across the IgE-Fc dimer and favors the recognition of $\mathrm{IgE}$ in an open conformation different from its FceRI- or CD23-bound conformations. Moreover, it binds IgE with significantly higher affinity than omalizumab and shows a correspondingly enhanced inhibition of IgE binding to FceRI and basophil activation. In contrast and despite its higher affinity for IgE, ligelizumab is inferior to omalizumab in preventing IgE binding to CD23. Structural analysis indicates that differences in the ligelizumab epitope and spatial orientation on $\operatorname{IgE}$ contribute to this differential inhibition. We further observe that ligelizumab features the ability to reduce IgE production in peripheral blood mononuclear cell (PBMC) cultures, a process which may be mediated by its ability to bind IgE:CD23 complexes at the surface of B-cells. Together, our data provide a structural and mechanistic foundation for understanding why ligelizumab exerts a qualitatively and functionally distinct inhibition profile from omalizumab and is superior in suppressing FceRI-dependent allergic reactions in vitro, in a passive systemic anaphylaxis mouse model in vivo and in clinical studies with chronic spontaneous urticaria patients ${ }^{31}$.

\section{Results}

Ligelizumab binding characteristics. A central mechanism of therapeutic anti-IgE antibodies is the neutralization of free serum
IgE. The binding affinity for IgE may therefore be a major determinant of clinical efficacy. To assess binding kinetics of ligelizumab to human IgE, we performed surface plasmon resonance (SPR) measurements. Human monoclonal Sus11-IgE was displayed on the chip surface via the non-competitive anti-IgE capture antibody Le27 (ref. ${ }^{32}$ ). Different concentrations of ligelizumab IgG as well as its $\mathrm{F}\left(\mathrm{ab}^{\prime}\right)_{2}$ and Fab fragments were measured in consecutive cycles on surface displayed IgE (Fig. 1a and Supplementary Fig. 1a, b). As a comparison, the same measurements were performed with the therapeutic anti-IgE antibody omalizumab IgG and its $\mathrm{F}\left(\mathrm{ab}^{\prime}\right)_{2}$ or Fab fragments (Fig. $1 \mathrm{~b}$ and Supplementary Fig. 1c, d). The individual association $\left(k_{\mathrm{a}}\right)$ and dissociation $\left(k_{\mathrm{d}}\right)$ constants were calculated using a 1:1 binding langmuir curve fitting model (Table 1, Fig. 1a, b and Supplementary Fig. 1a-d). With a $K_{\mathrm{D}}$ of $35 \mathrm{pM}$, the interaction of ligelizumab Fab with IgE was $\sim 88$-fold stronger than the binding of omalizumab Fab. While the measurements of the association constants for ligelizumab or omalizumab Fab revealed rather small differences, ligelizumab featured an $\sim 15$-times lower dissociation rate. The difference in affinity was further confirmed by dose-dependent titration of ligelizumab or omalizumab IgG and its $\mathrm{F}\left(\mathrm{ab}^{\prime}\right)_{2}$ or Fab fragments on surface displayed IgE in a titration ELISA (Supplementary Fig. 1e-g).

$\operatorname{IgE}$ is a flexible protein, which undergoes conformational rearrangements depending on its interaction partner ${ }^{33}$. Various studies have demonstrated that IgE binds FceRIa in an open C\&3 domain conformation ${ }^{6}$, while CD23-bound IgE adopts a closed Ce3 conformational state ${ }^{34}$ and that these receptor interactions are mutually exclusive ${ }^{35}$. We have previously engineered an IgE$\mathrm{Fc}_{3-4}$ variant (C335) that is trapped in a closed FceRIa incompatible conformation ${ }^{36}$, while the wild-type $\operatorname{IgE} \mathrm{Fc}_{3-4}$ (C328) can adopt an open FceRIa-binding state (Fig. 1c). To assess whether ligelizumab features binding preference for one of these conformational states, we measured its interaction with $\mathrm{C} 328$ or $\mathrm{C} 335 \mathrm{IgE}-\mathrm{Fc}_{3-4}$ by SPR. Ligelizumab recognized the wild-type $\mathrm{C} 328 \mathrm{IgE} \mathrm{Fc}_{3-4}$ variant with $\sim 60$-fold higher affinity (Fig. 1d, e and Supplementary Table 1). In contrast, omalizumab showed similar binding to both conformations (Table 1 and Fig. $1 \mathrm{~g}, \mathrm{~h}$ ). These findings were further confirmed by ELISA, in which ligelizumab again showed preferential binding to wild-type C328 IgE- $\mathrm{Fc}_{3-4}$, while omalizumab did not discriminate between the two conformational variants (Fig. 1f, i).

To obtain structural insight into the ligelizumab binding epitope on IgE, we solved the crystal structure of the C328 IgE$\mathrm{Fc}_{3-4}$ fragment bound to the single chain fragment variable ( $\mathrm{scFv}$ ) construct of ligelizumab to a resolution of $3.65 \AA$ (Supplementary Table 2). The crystal structure (PDB ID: 6UQR) shows two ligelizumab scFvs binding across the IgE dimer, with each $s c F v$ forming interactions with both $\mathrm{C} \varepsilon 3^{3}$ domains (Fig. 1j, k). The majority of the ligelizumab interaction is mediated through $\mathrm{VH}$ domain interactions with one of the $\mathrm{C} \varepsilon 3$ domains, with a total buried surface area of $\sim 1200 \AA^{2}$. This primary contact is formed by $\sim 15$ residues of the ligelizumab VH domain with heavy chain complementary determining region 1 (HCDR1) residues W31, Y32 and W33 forming key contacts at the center of the interface (Fig. 1l, m). By comparison, HCDR3 extends along the inner face of the $\mathrm{C} \varepsilon 3$ domain and makes more peripheral contacts with IgE. The ligelizumb VH domain contacts 21 residues of the IgE, centered around Q417, R419 and M430 (Fig. 1l, m). Ligelizumab contacts with the second Ce3 domain appear relatively minor, burying only $\sim 170 \AA^{2}$ of accessible surface area and involving only 6 residues in VL with 4 residues in IgE. In this cross-dimer contact, ligelizumab VL residues interact with the IgE loop containing its conserved $\mathrm{N}$-linked glycosylation site at residue 394. These contacts likely contribute little to overall ligelizumab affinity, but the cross-dimer interactions would restrict the 
a

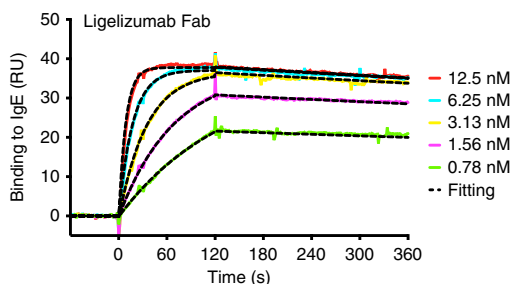

d

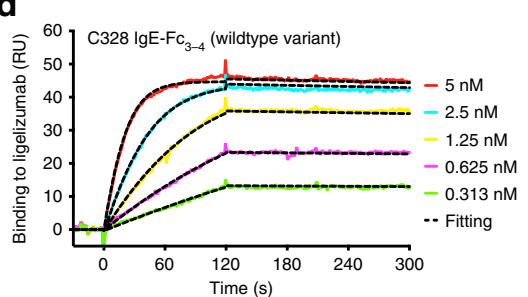

g

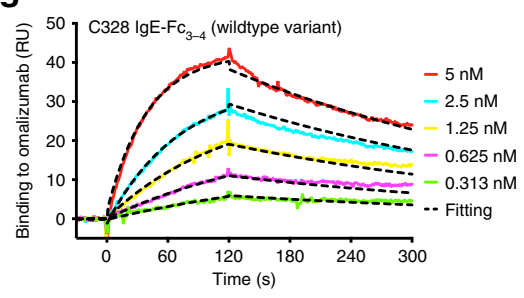

j

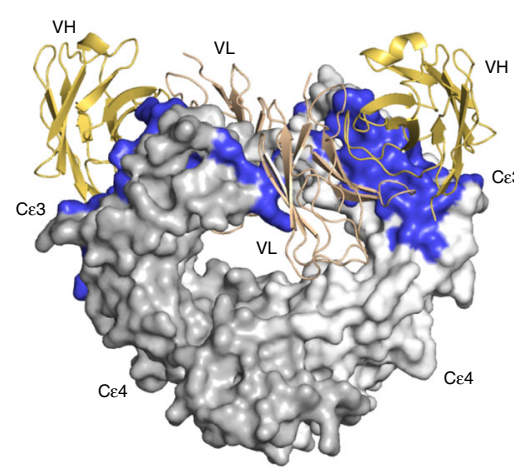

I

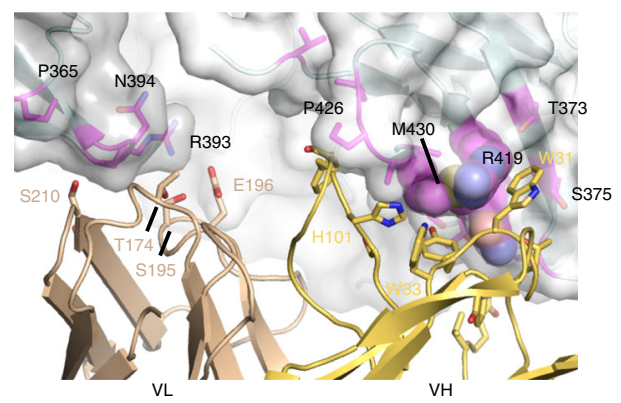

b
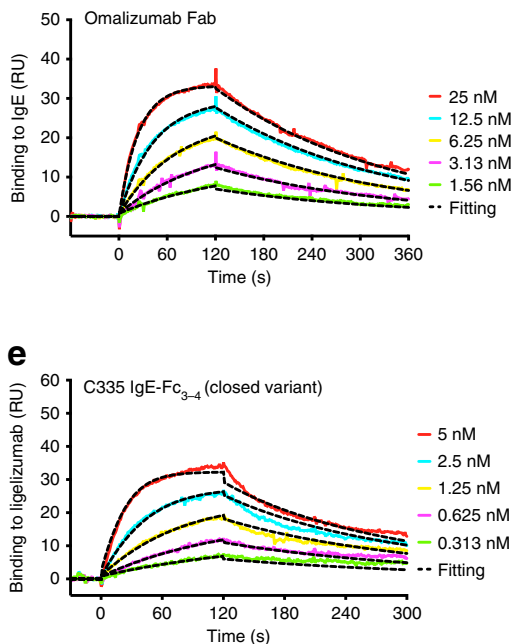

h

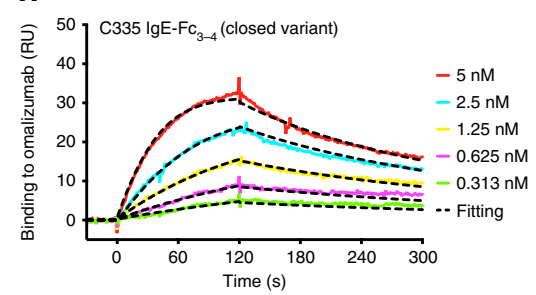

$\mathbf{k}$

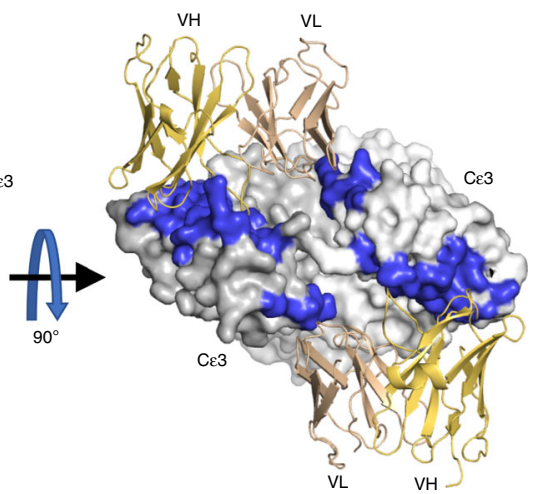

m

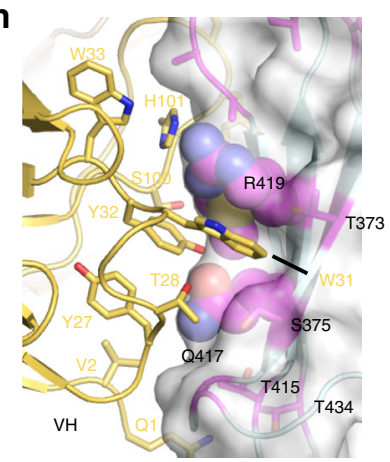

C
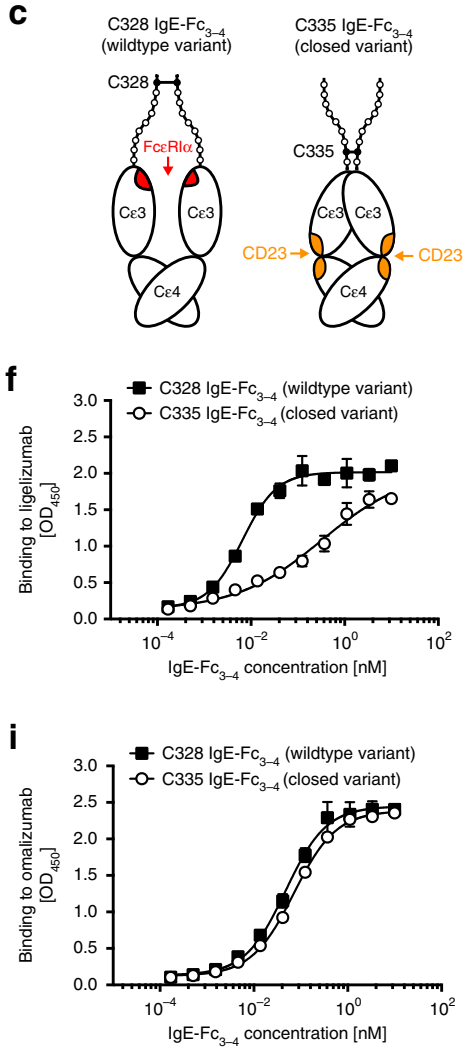

n

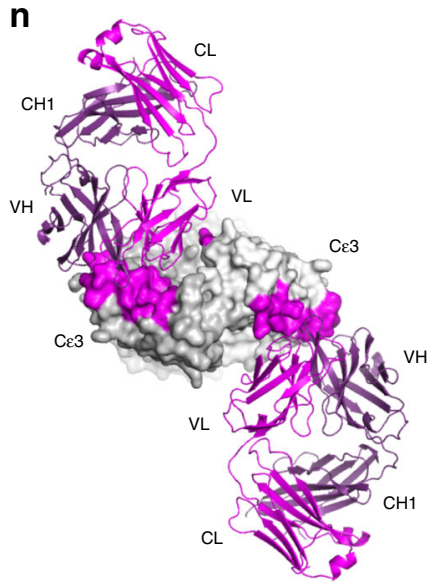

o

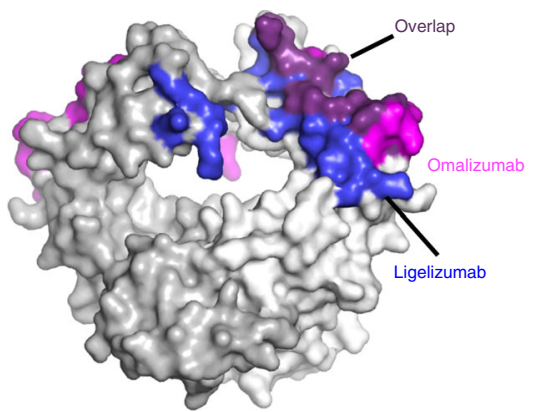

conformations accessible to the $\mathrm{C} \varepsilon 3$ domain. The structural data indicate that in the ligelizumab complex, the $\operatorname{IgE} \mathrm{C} \varepsilon 3$ dimer appears more open, with a V336-V336 distance of $17 \AA$ as compared to $\sim 12 \AA$ in the constrained C335 IgE-Fc $\mathrm{F}_{3-4}$ variant and consistent with its reduced affinity for this C335 mutant.
Ligelizumab and omalizumab clearly bind to different epitope structures on the IgE-Fc dimer; however, they share a significant overlapping region (Fig. 1n, o). In addition, the angle of binding of the two antibodies relative to the IgE-Fc domain also differs, affecting their respective functions in receptor inhibition. 
Fig. 1 Binding kinetics of ligelizumab or omalizumab on recombinant human IgE. a, b Association and dissociation of ligelizumab (a) and omalizumab (b) Fab fragments to human recombinant Sus11-IgE by SPR. Each color refers to an individual measurement cycle. Curves were fitted (black dashed) using a 1:1 langmuir binding model. c Wildtype C328 and mutant C335 IgE- $\mathrm{Fc}_{3-4}$. d, e Binding of wt C328 IgE- $\mathrm{Fc}_{3-4}$ (d) and mut C335 IgE-Fc $\mathrm{C}_{3-4}$ variants (e) to ligelizumab IgG by SPR. $\mathbf{f}$ Binding of wt C328 IgE- $\mathrm{Fc}_{3-4}$ or mut C335 IgE- $\mathrm{Fc}_{3-4}$ to ligelizumab IgG by ELISA (technical duplicates as mean \pm SEM).

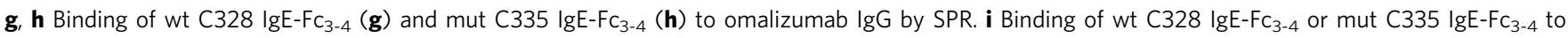
omalizumab IgG by ELISA (technical duplicates as mean \pm SEM). $\mathbf{j}-\mathbf{m}$ Crystal structure of ligelizumab single chain Fv (scFV) bound to wt C328 IgE-Fc $3-4$ (PDB ID: 6UQR). IgE-Fc $3-4$ dimer in surface representation (white and light gray). Ligelizumab epitope residues shown in blue. The ligelizumab scFv is shown in cartoon format (light orange and wheat). $90^{\circ}$ rotations with perpendicular (j) and parallel (k) view to IgE-Fc twofold axis. $\mathbf{I}, \mathbf{m}$ Contact interface between ligelizumab VH and VL CDR loops with the two IgE C 83 domains. I Orientation along the IgE twofold axis. $\mathbf{m}$ Orientation from the side of the $\mathrm{VH}$ : IgE-Fc interaction. Ligelizumab VH domain interaction is centered around IgE residues R419, M430 and Q417. Ligelizumab residue W31 packs into a pocket on IgE, with additional HCDR1 residues (Y32 and W33) forming interactions that straddle the central R419/M430/Q417 site. Interactions of the VL domain with IgE are limited and located adjacent to residue N394. $\mathbf{n}$ Structure of omalizumab bound to IgE-Fc (PDB ID: 5HYS ${ }^{41}$ ) oriented as in $\mathbf{k}$. Omalizumab is shown in ribbon format with heavy chains (violet) and light chains (magenta). IgE is shown in surface format with interface residues (magenta). $\mathbf{o}$ Overlap of ligelizumab and omalizumab epitopes. Residues unique to omalizumab interactions (magenta) and unique to ligelizumab are (blue) and those that interact with both antibodies (violet) are shown. Source data are provided as Source Data file.

\begin{tabular}{|c|c|c|c|}
\hline Anti-lgE antibody & $\begin{array}{l}\text { Association } k_{\mathrm{a}} \\
\left(\mathbf{M}^{-1} \mathbf{s}^{-1}\right)\end{array}$ & $\begin{array}{l}\text { Dissociation } k_{\mathrm{d}} \\
\left(\mathrm{s}^{-1}\right)\end{array}$ & $\begin{array}{l}\text { Affinity } \\
K_{\mathrm{D}}(\mathrm{pM})\end{array}$ \\
\hline Ligelizumab IgG & $1.8 \times 10^{6}$ & $3.3 \times 10^{-5}$ & 17.8 \\
\hline Omalizumab IgG & $9.1 \times 10^{5}$ & $2.4 \times 10^{-3}$ & 2659 \\
\hline Ligelizumab $\mathrm{F}\left(a \mathrm{~b}^{\prime}\right)_{2}$ & $4.2 \times 10^{6}$ & $5.1 \times 10^{-5}$ & 12.1 \\
\hline Omalizumab $\mathrm{F}\left(\mathrm{ab} \mathrm{b}^{\prime}\right)_{2}$ & $8.7 \times 10^{5}$ & $2.6 \times 10^{-3}$ & 2998 \\
\hline Ligelizumab Fab & $9.2 \times 10^{6}$ & $3.2 \times 10^{-4}$ & 35.0 \\
\hline Omalizumab Fab & $1.5 \times 10^{6}$ & $4.6 \times 10^{-3}$ & 3090 \\
\hline
\end{tabular}

Characterization of the ligelizumab IgE inhibition profile. Given that ligelizumab has superior affinity for IgE than omalizumab, we aimed to compare their potency in preventing IgE binding to FceRIa using ELISA and cell-based assays. For ELISA assays, we used a Sus11-IgE concentration $(0.78 \mathrm{nM})$ at the midpoint of its binding titration with FceRIa, which falls within physiological IgE concentrations (Supplementary Fig. 2a), to investigate dose-dependent inhibition of IgE-binding to FceRIa by ligelizumab or omalizumab IgG (Fig. 2a). The results show that ligelizumab inhibits IgE-binding to FceRIa with a 20-fold higher potency than omalizumab. We also measured ligelizumaband omalizumab-mediated inhibition of IgE-binding to isolated human primary basophils by flow cytometry. These cells express high levels of CD123, CD193 and carry FceRIa-bound IgE on their surface (Fig. 2b). After removing endogenous IgE from the isolated basophils ${ }^{25}$, we used a physiologically relevant concentration of $2 \mathrm{nM}$ of JW8-IgE (Supplementary Fig. 2b) in the inhibition assay. IgE was pre-incubated with varying concentrations of ligelizumab or omalizumab IgG (Fig. 2c). Ligelizumab blocked IgE binding with greater potency, consistent with its higher affinity and with the ELISA results.

Given the difference in their binding epitopes on $\operatorname{IgE}$, we further explored the ability of ligelizumab and omalizumab to inhibit IgE-binding to CD23. Due to the low affinity of the CD23 interaction, pre-formed IgE:antigen complexes were used in this ELISA. A concentration of $70 \mathrm{nM}$ IgE:antigen complexes (Supplementary Fig. 2c) was incubated with physiologically relevant amounts of ligelizumab or omalizumab IgG prior to the addition to immobilized CD23. Interestingly, despite its higher affinity for IgE, ligelizumab showed a fourfold weaker inhibition of IgE-binding to CD23, as compared to omalizumab (Fig. 2d). To further evaluate CD23 competition on cells, we measured ligelizumab- and omalizumab-mediated inhibition of IgE-binding to CD23 by flow cytometry using the CD19-/CD23expressing leukemia B-cell line RPMI8866 (Fig. 2e). A physiologically relevant IgE concentration of $12.5 \mathrm{nM}$ (Supplementary Fig. 2d) was pre-incubated with ligelizumab or omalizumab IgG in varying concentrations. In agreement with the ELISA data, we observed weaker inhibition of IgE-binding to CD23 on RPMI8866 cells with ligelizumab than with omalizumab (Fig. 2f). Thus, the two anti-IgE antibodies reveal a qualitatively distinct inhibition profile for the two IgE receptor pathways with ligelizumab being more potent and more selective for inhibition of IgE binding to FceRI.

Previous studies have reported that human $\mathrm{BDCA1}^{+}$dendritic cells (DCs) constitutively express surface FceRI resulting in rapid binding and endocytosis of serum $\operatorname{IgE}^{37}$. The mechanism of FceRI-mediated IgE:antigen complex uptake and presentation by DCs has further been proposed to promote Th2 immune responses ${ }^{38,39}$. To assess the effect of ligelizumab and omalizumab on IgE-binding and IgE:antigen complex internalization with DCs, we isolated human BDCA1 ${ }^{+}$DCs from whole-blood donations (Supplementary Fig. 3a) and assessed IgE binding and internalization in the presence of ligelizumab and omalizumab. In contrast to the results obtained with basophils, both anti-IgE antibodies dose-dependently inhibited binding of $\operatorname{IgE}$ with the same efficacy (Supplementary Fig. 3b). By analyzing IgE receptors expression on $\mathrm{BDCA}^{+}{ }^{+} \mathrm{DCs}$, we found evidence for coexpression of FceRIa and CD23, which explains the lack of superior inhibition of ligelizumab in this experimental setup (Supplementary Fig. 3c). Next, we compared the uptake of IgE: antigen complexes of basophils and $\mathrm{BDCA}^{+}$DCs. Maximal internalization was reached after $4 \mathrm{~h}$ of incubation for basophils and $8 \mathrm{~h}$ for DCs as detected by $\mathrm{pH}$-sensitive IgE staining (Supplementary Fig. 3d). In line with previous results, ligelizumab inhibited the IgE:antigen complex uptake in basophils more efficiently than omalizumab (Supplementary Fig. 3e). Interestingly, only $\mathrm{F}\left(\mathrm{ab}^{\prime}\right)_{2}$ fragments prevented complex internalization in DCs, whereas the full-length antibodies increased the uptake presumably through engagement of $\mathrm{Fc} \gamma$-receptors that are present on the surface of these cells (Supplementary Fig. 3f).

The crystal structure of the ligelizumab svFv:IgE-Fc ${ }_{3-4}$ complex provides detailed insights into its ability to inhibit FceRI and CD23 binding (Fig. 2g-k). Views of the IgE:ligelizumab and IgE: FceRIa complexes along the IgE dimer axis show that the two ligelizumab scFvs mimic the arrangements of FceRI and IgE Ce2 domains on either side of the central pair of $\mathrm{C} \varepsilon 3$ domains (Fig. $2 \mathrm{~g}$, $\mathrm{h})$. Therefore, at least three mechanisms could contribute to the ability of ligelizumab to efficiently block FceRI binding. First, one of the ligelizumab scFvs occupies a largely overlapping volume with FceRIa, indicating that substantial steric conflicts between ligelizumab and FceRIa prevent their simultaneous binding (Fig. 2g, h). Second, the interaction footprints of ligelizumab 
a

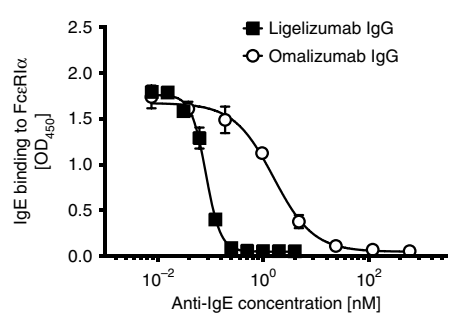

d

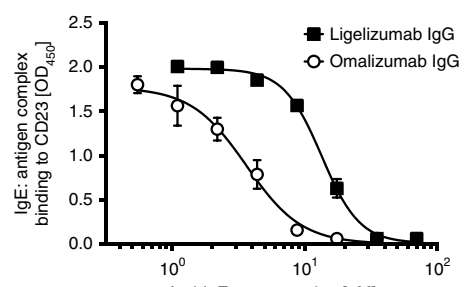

b

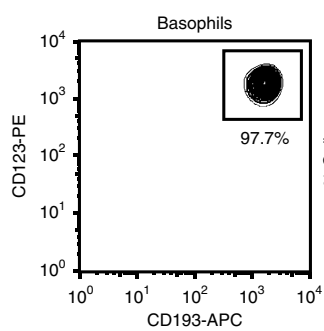

e

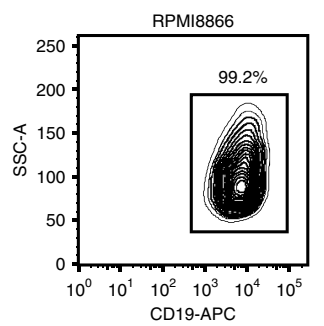

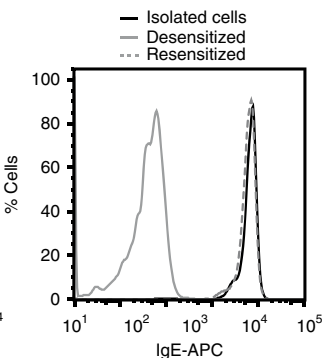

IgE-APC
C
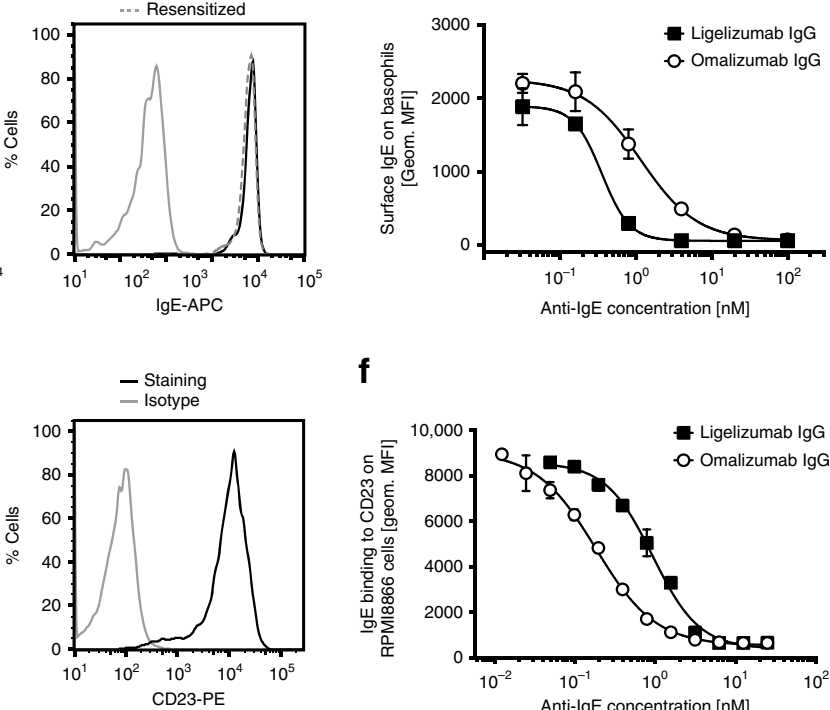

$\mathbf{f}$

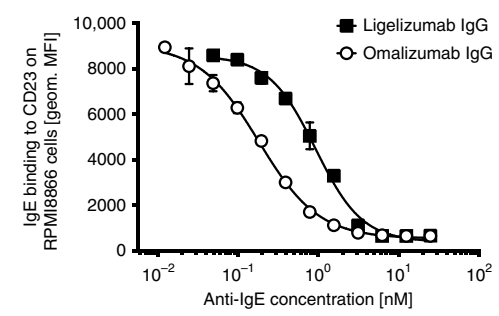

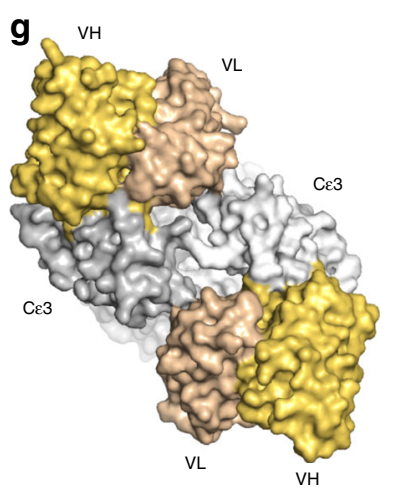

j

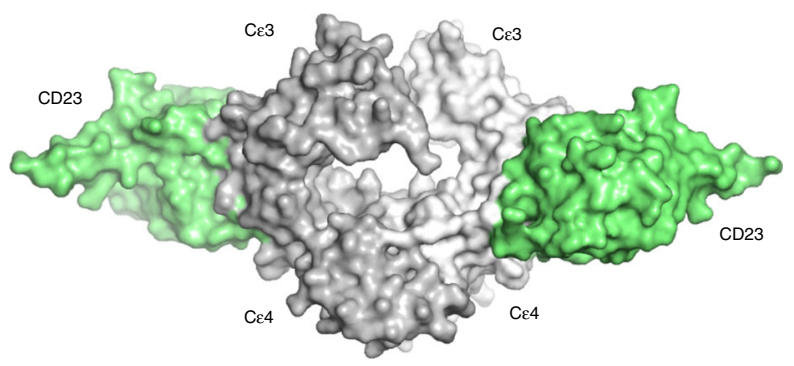

i
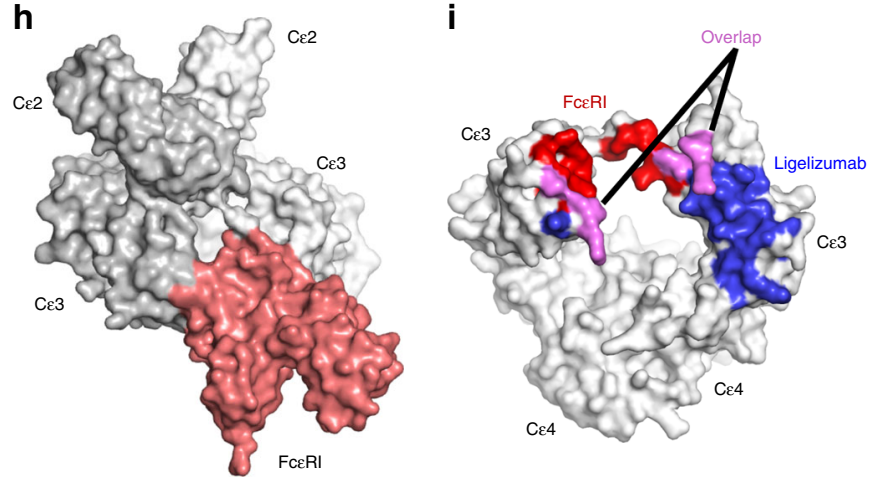

$\mathbf{k}$

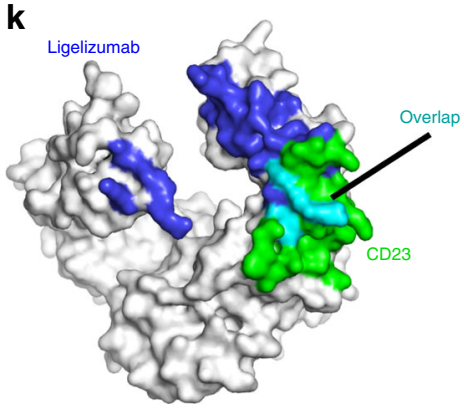

Fig. 2 Inhibition of IgE binding to FceRI $\alpha$ and CD23 by ligelizumab or omalizumab. a Inhibition of IgE binding to FceRl $\alpha$ through ligelizumab or omalizumab IgG by ELISA. b Isolated primary human blood basophils are gated as SSClow, FSClow, CD123+, CD193+ double-positive cells. A histogram of basophil surface IgE levels before (black line) and after desensitization with $5 \mu \mathrm{M}$ disruptive-anti-IgE DARPin bi53_79 (gray line) and after resensitization with recombinant human JW8-IgE (dashed gray line) is shown. c Inhibition of IgE binding to FcERl $\alpha$ on isolated bi53_79-treated basophils by ligelizumab or omalizumab IgG. Binding curves were fitted using a non-linear regression model. d Inhibition of IgE:antigen complex binding to CD23 by ligelizumab or omalizumab IgG by ELISA. e Surface expression of CD23 on RPMI8866 cells by flow cytometry. $\mathbf{f}$ Inhibition of IgE binding to RPMI8866 cells by ligelizumab or omalizumab IgG. Binding curves (technical duplicates as mean \pm SEM) were fitted using a non-linear regression model. $\mathbf{g}$-i Ligelizumab sterically blocks FceRI binding overlaps with receptor-binding residues in both $\operatorname{lgE}$ subunits. $\mathbf{g}$ Ligelizumab complex in surface representation with the view along the $\mathrm{IgE}$ twofold axis (PDB ID: 6UQR). VH and VL domains are (light orange and wheat) and lgE subunits (white and light gray) are shown. $\mathbf{h}$ The structure of IgE$\mathrm{Fc}_{2-4}$ with FceRl $\alpha$ (PDB ID: $2 \mathrm{Y}^{5} \mathrm{Q}^{53}$ ) in surface format, with the receptor (salmon) and IgE chains (white and light gray). One ligelizumab scFv sterically blocks receptor binding, while second scFv overlaps the position of the IgE C $\varepsilon 2$ domains. i Overlap of IgE residues involved in both FceRI and ligelizumab binding. $\operatorname{lgE}-\mathrm{Fc}_{3-4}$ in a surface representation is shown with common contacts shared by ligelizumab and FceRl $\alpha$ (magenta), FceRl $\alpha$-specific contacts (red) and ligelizumab-specific (blue). $\mathbf{j}$ Structure of CD23:IgE-Fc $3-4$ complex (PDB ID: 4EZM ${ }^{57}$ ). IgE in surface representation with CD23 (light green). $\mathbf{k}$ IgE binding sites for CD23 have minimal overlap with ligelizumab epitope. IgE residues involved solely in ligelizumab binding (blue), those involved only in CD23 binding (green) and the overlapping contact residues (cyan) are shown. a, c, d, f Data shown for technical duplicates as mean \pm SEM. Source data are provided as Source Data file. 
and FceRIa on IgE show that both ligands share a number of identical binding residues on IgE (Fig. 2i), indicating potential for direct, though limited, competition for subsite binding. Third, the binding of ligelizumab across the $\operatorname{IgE}$ dimer restricts the arrangement of the $\mathrm{C} \varepsilon 3$ domains into a conformation that is incompatible with FceRI binding (Fig. 2g, h). Furthermore, ligelizumab binding to intact IgE would also displace C\&2 domains, generating a more linear structure that might interfere with FceRIa binding ${ }^{40}$.

$\mathrm{CD} 23$ interacts with $\mathrm{IgE}-\mathrm{Fc}$ at the hinge region between $\mathrm{C} \varepsilon 3$ and $\mathrm{C} \varepsilon 4$ domains (Fig. 2j), favoring a closed conformation of $\mathrm{C} \varepsilon 3$ domains ${ }^{34}$. Comparison of the CD23 and ligelizumab interaction sites on IgE indicates relatively minor overlap between binding sites of these two IgE ligands (Fig. 2k). Furthermore, the orientation of the ligelizumab VHVL domains on IgE (Fig. 2g) indicates that the ligelizumab Fab would project away from the IgE and would not sterically overlap bound CD23, suggesting that competition for IgE surface subsites and the stabilization of an open C 83 conformation would be the primary mechanism of CD23 inhibition. In contrast, omalizumab-mediated inhibition of CD23 binding to IgE is effected by both substantial steric overlap between omalizumab and CD23, and through direct competition for IgE-binding residues by the omalizumab heavy chain ${ }^{41}$. Comparisons of the omalizumab and ligelizumab complexes with IgE (Fig. 1j-o and Supplementary Fig. 4) show that the antibody binding footprints and orientations contribute to the significant differences in their relative abilities to inhibit CD23 or FceRIa binding.

Determination of ability to disrupt FceRI:IgE complexes. We previously reported that omalizumab in addition to its ability to neutralize free serum $\operatorname{IgE}$ accelerates $\operatorname{IgE}$ dissociation from the surface of FceRIa-expressing cells at concentrations well above its $K_{\mathrm{D}}{ }^{24,25}$. To test whether ligelizumab shares this additional mode of action, we assessed its ability to actively remove FceRIa-bound IgE. Using SPR, we pre-complexed monoclonal human Sus11-IgE with immobilized recombinant human FceRIa. Subsequently, 0.25-1 $\mu \mathrm{M}$ ligelizumab IgGs were continuously added for $8 \mathrm{~h}$ to FceRIa-bound IgE. No dissociation above buffer baseline was observed for any of the ligelizumab concentrations (Fig. 3a). In contrast, omalizumab IgG showed dose-dependent removal of IgE from FceRIa at concentrations $\leq 1 \mu \mathrm{M}$ as judged by the steadily declining surface signal (Fig. 3b). Additionally, we evaluated ligelizumab- and omalizumab-mediated IgE dissociation from FceRIa on the cell surface of isolated primary human basophils. Using the same concentrations of anti-IgE antibodies and antibody fragments, we quantified IgE cell surface levels after 3 and 6 days of cell culture in the presence of the respective antiIgE antibody (Fig. 3c). Again, omalizumab but not ligelizumab treatment resulted in dose-dependent removal of surface IgE.

We have previously observed that omalizumab can form stable ternary complexes with FceRIa-bound $\mathrm{IgE}_{-} \mathrm{Fc}_{3-4}$ fragments without removing them from the receptor ${ }^{25,41}$. This is due to the exposure of one of the omalizumab epitopes that is buried by $\mathrm{C} \varepsilon 2$ domains in the intact IgE. We therefore assessed whether ligelizumab exhibits similar binding behavior using SPR. IgE$\mathrm{Fc}_{3-4}$ was pre-complexed with immobilized FceRIa and ligelizumab IgG was subsequently added. Interestingly, we observed rapid disruption of $\mathrm{IgE}_{-} \mathrm{Fc}_{3-4}$ :FceRIa complexes (Fig. 3d). This was not the case for omalizumab IgG, which showed pronounced binding to $\mathrm{IgE}_{-} \mathrm{Fc}_{3_{-}}$: $\mathrm{Fc}$ (eRIa complexes without obvious disruptive activity (Fig. 3e). The anti-IgE antibody Le27 $7^{32}$, which binds non-competitively to a $\mathrm{C} \varepsilon 4$ domain epitope and was used as a control, also recognized FceRIa-bound $\mathrm{IgE}_{-} \mathrm{Fc}_{3-4}$ in a dosedependent manner (Fig. 3f).
The structure of the IgE- $\mathrm{Fc}_{3-4}$ :ligelizumab $\mathrm{scFv}$ complex suggests a conformational mechanism to explain the ability of ligelizumab to disrupt these preformed $\operatorname{IgE}_{-F_{3} 4}$ :FceRIa complexes. Superposition of the ligelizumab and FceRI complex structures through the $\mathrm{C} \varepsilon 3$ domain that forms the majority of the exposed ligelizumab epitope shows significantly different arrangements of the second Ce3 domain (Fig. 3g, h). While FceRI binding requires an asymmetric arrangement of the two $\mathrm{C} \varepsilon 3$ domains, ligelizumab binding restricts the position of the second Ce3 domain, causing an overall shift in FceRI-binding loops of $\sim 11 \AA$ (Fig. $3 \mathrm{~g}, \mathrm{~h}$ ). Ligelizumab binding forces the C $\mathrm{C} 3$ domains into a more symmetrical arrangement that closely aligns with the IgE dimer twofold axis defined by the Ce4 domains and that is incompatible with FceRI binding. The ability of ligelizumab to bind and dissociate the $\operatorname{IgE}-\mathrm{Fc}_{3-4}: \mathrm{FccR}$ I complexes suggests that the complex can dynamically access conformational states in which the secondary $\mathrm{C} \varepsilon 3$ domain does not sterically block ligelizumab binding.

To further investigate whether ligelizumab accelerates dissociation of FceRI-bound IgE-Fc $\mathrm{C}_{3-4}$ on allergic effector cells, we isolated primary human basophils, removed endogenous $\operatorname{IgE}$ from the cell surface using a disruptive anti-IgE DARPin ${ }^{\circledR}$ protein, re-sensitized the cells with either $100 \mathrm{nM}$ JW8-IgE or $\mathrm{C} 328 \mathrm{IgE}_{-} \mathrm{FC}_{3-4}$ and subsequently added ligelizumab or omalizumab IgG. As expected, the IgE surface levels of JW8-IgE resensitized cells did not show any decrease upon treatment with either of the two anti-IgE antibodies at these concentrations as measured by flow cytometry (Fig. 3i). Additionally, we analyzed the activation status of these cells by measuring CD63 surface levels. In line with our SPR data suggesting the inability of ligelizumab or omalizumab to recognize FceRI-bound full length IgE (Supplementary Fig. 5a-e), no activation was observed for either of the two anti-IgE antibodies (Fig. 3j). Re-sensitizing cells with $\mathrm{IgE}-\mathrm{Fc}_{3-4}$, instead of intact IgE, revealed that ligelizumab but not omalizumab treatment resulted in a dose-dependent reduction of surface IgE-Fc $\mathrm{F}_{3-4}$ levels on cells (Fig. 3k). Strikingly and in line with the corresponding binding data, we found that omalizumab but not ligelizumab can activate basophils resensitized with $\mathrm{IgE}-\mathrm{Fc}_{3-4}$ in a dose-dependent manner (Fig. 3l).

Engagement of CD23:IgE complexes. CD23 is known to play an important role in enhancing IgE-mediated allergen presentation by antigen presenting cells and in the regulation of IgE production by B-cells ${ }^{5}$. Various studies have demonstrated that compounds targeting CD23 or CD23-bound IgE on B-cells can inhibit IgE production $22,42-44$. Since the crystal structure of ligelizumab with $\mathrm{IgE}-\mathrm{Fc}_{3-4}$ showed only a minor overlap with CD23-binding residues, we assessed whether ligelizumab might also be able to bind IgE:CD23 complexes. For this purpose, we performed SPR experiments in which JW8-IgE was pre-complexed with immobilized CD23 on the chip surface (Fig. 4a). Upon subsequent injection of different ligelizumab or omalizumab concentrations, the IgE binding signal immediately decreased, indicating that $\operatorname{IgE}$ is displaced from CD23 by both anti-IgE antibodies (Fig. 4b). To check whether ligelizumab or omalizumab IgG formed ternary complexes with the remaining CD23-bound IgE on the chip surface, we additionally injected a polyclonal anti-IgG antibody. While CD23:IgE:ligelizumab complexation could be revealed by anti-IgG antibody, only minor signal was detectable with omalizumab (Fig. 4c). To confirm these results on a cellular level, CD23-expressing RPMI8866 cells were pre-sensitized with 12.5 nM JW8-IgE, washed and subsequently treated with an equimolar concentration of ligelizumab, omalizumab or a control IgG. Both anti-IgE treatments resulted in a reduction of surface IgE levels as measured by quantifying remaining CD23-bound IgE (Fig. 4d). 

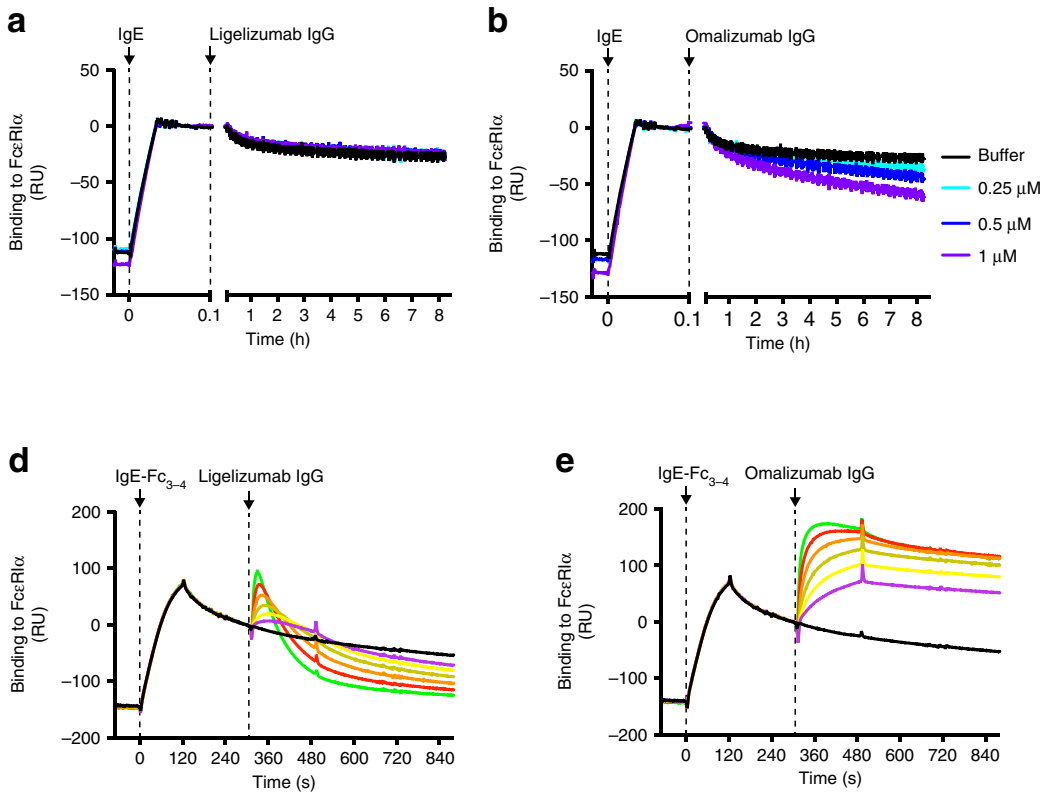

g

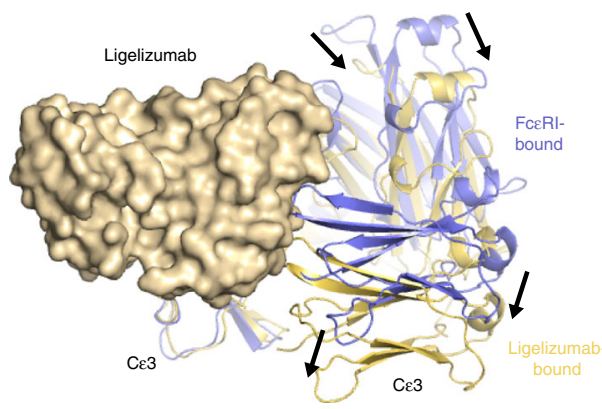

h

i

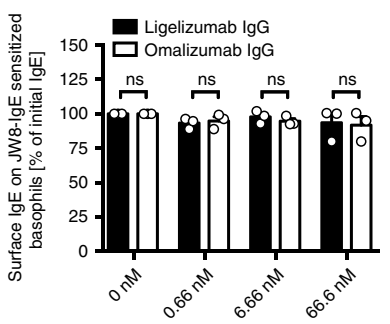

k
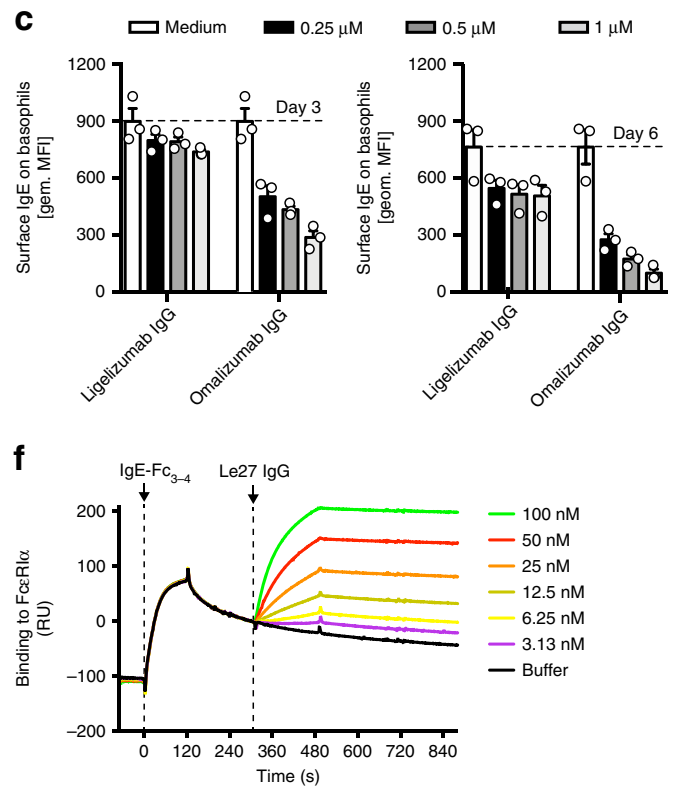

j

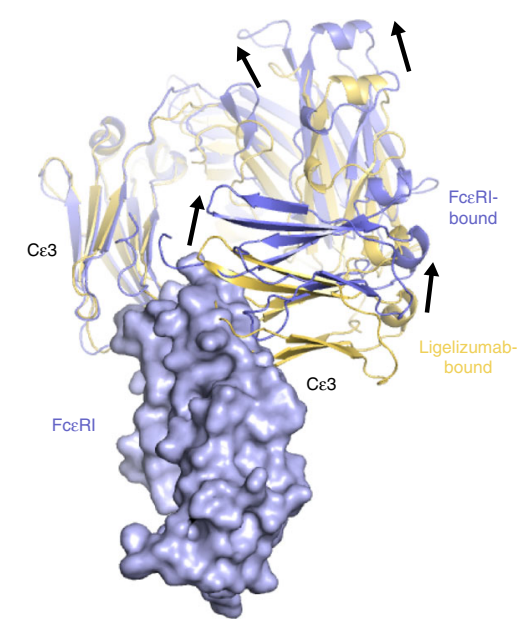

In line with the increased affinity of ligelizumab for free IgE, it showed more pronounced reduction of CD23-bound IgE cell surface levels. Nevertheless, we detected more prominent binding of ligelizumab to IgE remaining on the cell surface (Fig. 4e), which is in line with the SPR results. Additionally, when CD23 was blocked with an anti-CD23 compound prior to sensitization of the cells with JW8-IgE, almost no surface IgE could be detected and only minor binding of ligelizumab was observed, providing further evidence that ligelizumab binding to the RPMI8866 surface is dependent on the presence of CD23:IgE complexes. By adding $12.5 \mathrm{nM}$ JW8-IgE and an equimolar amount of ligelizumab to RPMI8866 cells, roughly one-third of the cells showed ligelizumab-binding on their surface (Fig. 4f, g). We additionally performed image stream flow cytometry analysis with the same experimental setup to provide direct visual evidence for ligelizumab-binding on IgE-sensitized RPMI8866 cells. All conditions showed clear staining for $\mathrm{CD} 23$ and IgE. Ligelizumab-treated cells were additionally positive for IgG staining (Fig. 4h) and showed clustering of IgE, indicating coaggregation of CD23-bound IgE by ligelizumab (Fig. 4i). Co-localization analysis of IgE and IgG staining in ligelizumabtreated cells resulted in a $73.7 \%$ overlapping signal, while Omalizumab again showed only very weak binding and negligible co-localization. 
Fig. 3 Disruption of FceRI:IgE complexes by ligelizumab or omalizumab. a and $\mathbf{b}$ Removal of FceRI pre-complexed human recombinant Sus11-lgE by ligelizumab (a) or omalizumab (b) IgG by SPR. Each color refers to an individual measurement cycle. Black line refers to baseline buffer control. Black arrows indicate time of injection. $\mathbf{c}$ Isolated primary human basophils $(n=3$ donors) were incubated for 3 or 6 days with indicated concentrations of ligelizumab and omalizumab IgG. Levels of cell surface IgE were quantified by flow cytometry (shown as mean \pm SEM). d-f Interaction of ligelizumab or omalizumab IgG with FceRI-bound IgE-Fc $3-4$. d and $\mathbf{e}$ Binding of ligelizumab (d) and omalizumab (e) IgG to FceRI pre-complexed human recombinant wt C328 IgE-Fc $3-4$ by SPR. $\mathbf{f}$ The monoclonal anti-lgE antibody Le27 was included as positive control. Each color refers to an individual measurement. Black line refers to baseline buffer control. Black arrows indicate the time of injection. $\mathbf{g}$, $\mathbf{h}$ Comparisons of ligelizumab- and FcERl $\alpha$-lgE complex structures.

Complexes were superimposed using the primary $\mathrm{VH}$-interacting $\mathrm{C} \varepsilon 3$ domain (corresponding to $\mathrm{FcER}_{\mathrm{R}} \alpha$ site 2 ), predominantly exposed in the IgE- $\mathrm{Fc}_{3-4}$ receptor-bound complex because of the absent $C_{\varepsilon} 2$ domains. A single ligelizumab $(\mathbf{g})$ and $F c \varepsilon R l \alpha(\mathbf{h})$ are shown in surface representations (light orange and light blue). Two conformations of the IgE-Fc are shown. $\mathbf{g}$ Binding of ligelizumab restricts secondary $\mathrm{C} \varepsilon 3$ domain conformation, preferring displacement (downward arrows). h FceRl $\alpha$ binding to ligelizumab-stabilized Fc conformation is sterically blocked, requiring displacement of the C 83 domain (upward arrows). Surface IgE levels (i) and percentage of activated cells (j) of JW8-IgE sensitized primary human basophils incubated for 30 min with ligelizumab or omalizumab IgG. Surface IgE levels (k) and percentage of activated cells (I) of IgE- $\mathrm{Fc}_{3-4}$ sensitized primary human basophils incubated for 30 min with ligelizumab or omalizumab IgG. i-I Biological triplicates are displayed as mean \pm SEM. Different conditions were compared to each other using two-way ANOVA with Sidak's multiple comparison. ${ }^{\star} P<0.05,{ }^{* \star} P<0.001$, ns $=$ not significant. Source data are provided as Source Data file.

Assessment of functional efficacy. Given the differences in binding affinities, epitopes and receptor competition profiles of ligelizumab and omalizumab, the two anti-IgE antibodies were further compared in functional assays. First, we assessed their inhibitory efficacy in a basophil activation test. To do so, endogenous IgE was removed from isolated primary human basophils using a disruptive anti-IgE DARPin ${ }^{\circledR}$ protein and cells were reloaded with different concentrations of NIP-specific JW8-IgE. Upon challenge of the resensitized cells with NIP $_{7}$-BSA antigen, basophil degranulation was quantified by measuring cell surface CD63 levels using flow cytometry (Fig. 5a). IgE dose-dependent basophil activation was observed at a constant antigen concentration of $100 \mathrm{ng} / \mathrm{ml} \mathrm{NIP}_{7}$-BSA (Supplementary Fig. 2e). A concentration of $0.68 \mathrm{nM}$ JW8-IgE was subsequently used for pre-incubation of ligelizumab or omalizumab IgG with JW8-IgE prior to re-sensitization of the cells. Antigen stimulation with $\mathrm{NIP}_{7}$-BSA showed dose-dependent inhibition of basophil activation with both anti-IgE antibodies, whereby ligelizumab was more potent than omalizumab (Fig. 5b), consistent with the greater inhibitory activity of ligelizumab in blocking the IgE: FceRIa interaction.

To further substantiate these findings in a representative FceRI-dependent in vivo allergy model, a passive systemic anaphylaxis test was performed using mice transgenic for the human FceRIa (huFceRIa tg) ${ }^{45}$. These mice can be passively sensitized with human antigen-specific IgE and challenged with the corresponding antigen to induce a systemic anaphylaxis (PSA). The mice were pre-treated with $10 \mu \mathrm{g}$ of anti-IgE antibody or PBS prior to sensitization with $20 \mu \mathrm{g}$ of NIP-specific JW8-IgE (Fig. 5c). The following day the mice were challenged with $200 \mu \mathrm{g}$ of $\mathrm{NIP}_{20}$-BSA and the body core temperature was measured. While mice treated with ligelizumab were completely protected against antigen-induced systemic anaphylaxis, omalizumabtreated animals showed only partial protection (Fig. 5d). These data reflect the degree of remaining IgE found on mast cells in peritoneal lavages from the mice, as identified by $\mathrm{CD}_{4}{ }^{+}, \mathrm{c}-\mathrm{kit}^{+}$, CD200R3 ${ }^{+}$cells by flow cytometry (Fig. 5e). Thus, the cell surface IgE levels closely correlate with the functional results of the PSA (Fig. 5f), with the ligelizumab-treated mice displaying only low levels of IgE on their peritoneal mast cells. These data further demonstrate the improved activity of ligelizumab in neutralizing free IgE and inhibiting FceRI-dependent allergic reactions in vivo.

A recent study has provided strong evidence that ligelizumab suppresses free serum IgE levels in humans for a significantly longer period-of-time than omalizumab after single dose injection $^{18}$. To assess whether this effect might additionally be related to ligelizumab-mediated inhibition of IgE production by B-cells, we performed $\operatorname{IgE}$ ELISpot assays. In vitro $\operatorname{IgE}$ synthesis is induced through incubation of isolated human PBMCs with IL-4 and anti-CD40 antibody ${ }^{46}$. Following this stimulation, we determined the number of IgE-producing B-cells in the cell culture by ELISpot assays and determined soluble IgE in culture supernatants. Incubation of the PBMCs with ligelizumab resulted in a significant reduction of IgE-producing B-cells in PBMC cultures, whereas the inhibition with omalizumab was less pronounced (Fig. $5 \mathrm{~g}, \mathrm{~h}$ ). In line with this finding, soluble IgE in culture supernatants of ligelizumab IgG or $\mathrm{F}\left(\mathrm{ab}^{\prime}\right)_{2}$-treated PBMCs was significantly decreased. Again, omalizumab IgG showed less efficient suppression and omalizumab $\mathrm{F}\left(\mathrm{ab}^{\prime}\right)_{2}$ had no effect on IgE production, strongly suggesting that its suppression is mediated via $F c \gamma$-receptors. Interestingly, blocking of $\mathrm{CD} 32 \mathrm{~b}$ (FcyRIIb) in PBMC cultures completely abrogated omalizumabmediated suppression of IgE production, whereas ligelizumabmediated suppression remained unaltered. Together our results demonstrate that the distinct IgE binding profiles and inhibition properties of ligelizumab and omalizumab significantly impact their functional activity.

\section{Discussion}

Here, we compare structural and functional studies of two antiIgE antibodies, ligelizumab and omalizumab, to better understand how their interactions with IgE impacts inhibitory mechanisms and predicts their potential therapeutic benefit. Ligelizumab and omalizumab recognize distinct binding epitopes in the $\operatorname{IgE} \mathrm{C} \varepsilon 3$ domain with some overlap and show different sensitivities to $\operatorname{IgE}$ conformation. Therefore, the two anti-IgE antibodies display different abilities to inhibit IgE interactions with FceRI and CD23 and feature a qualitatively distinct inhibition profile. Consequently, they greatly differ in their functional activities in blocking effector cell activation and $\operatorname{IgE}$ synthesis. While the increased affinity of ligelizumab for IgE explains superiority over omalizumab regarding neutralization of free serum $\mathrm{IgE}$, we have identified an additional mode of action for ligelizumab through the inhibition of IgE production, which may provide additional therapeutic benefit. We observe that ligelizumab is more efficient in suppressing FceRI-dependent allergic reactions in an in vivo model, while omalizumab may have advantages in blocking antigen presentation and transport processes that are dependent on IgE:CD23 interactions ${ }^{47,48}$. This balance of modulating IgE interactions with its two receptors, along with their associated functions, might have future consequences for the design of antiIgE therapeutics.

Our data confirm that ligelizumab does not recognize FceRIabound IgE, which represents the critical safety requirement for therapeutic anti-IgE antibodies. Interestingly, we observed that ligelizumab efficiently removes IgE-F $c_{3-4}$ fragments from FceRIa, 
a
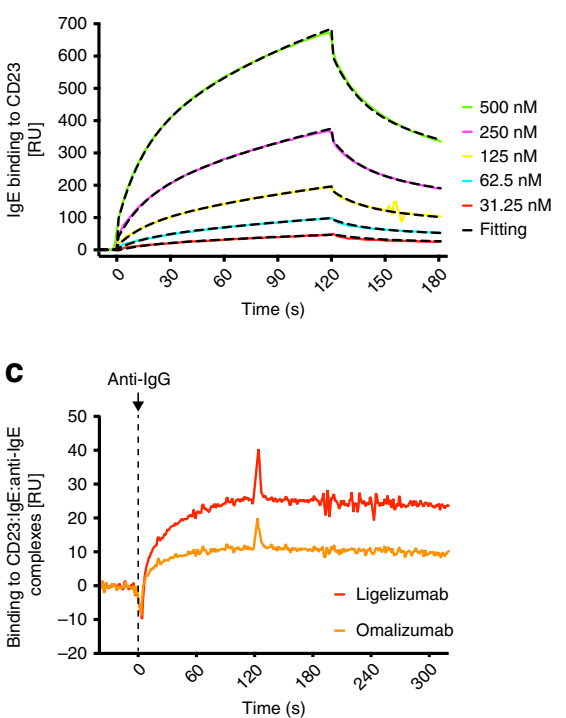

b

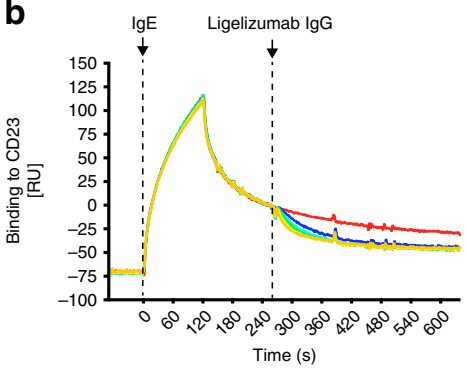

d

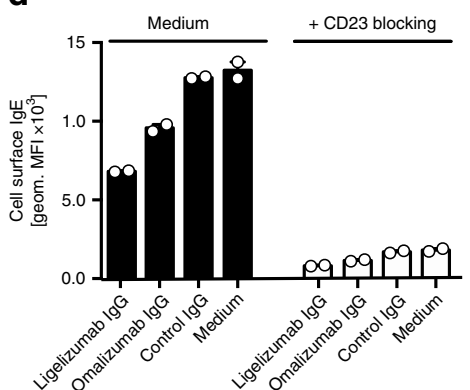

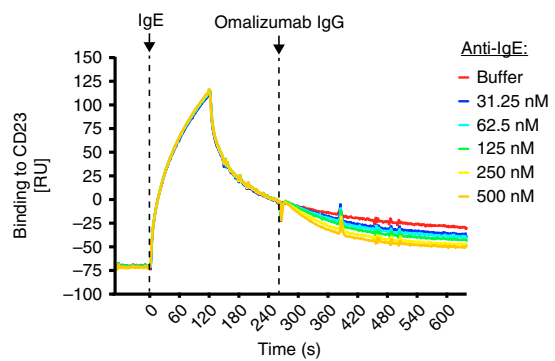

e

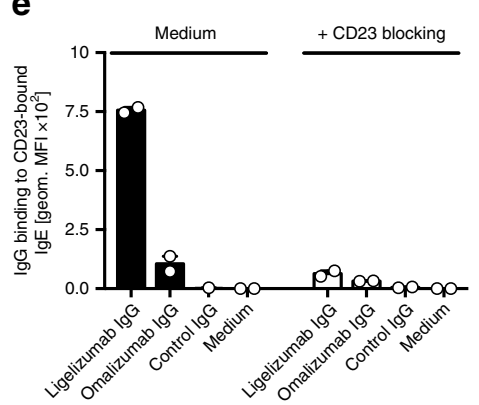

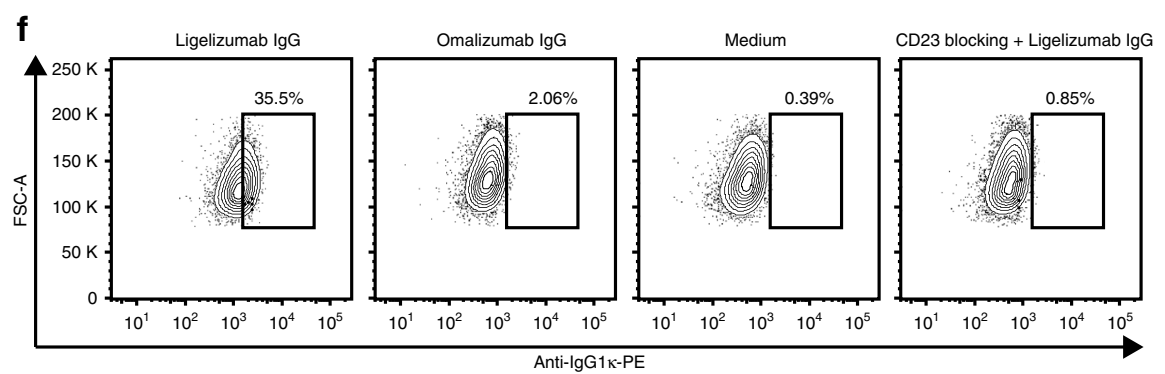

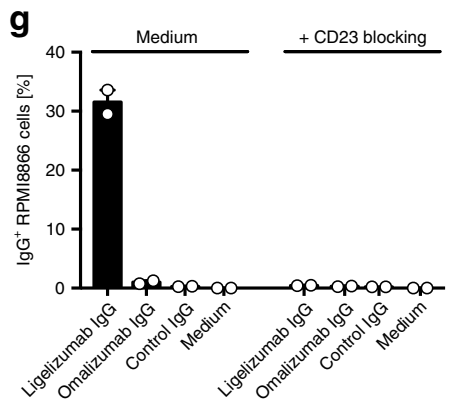

h

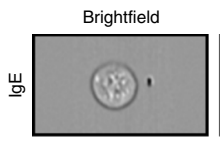

Anti-CD23
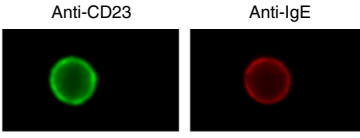

Anti-IgG
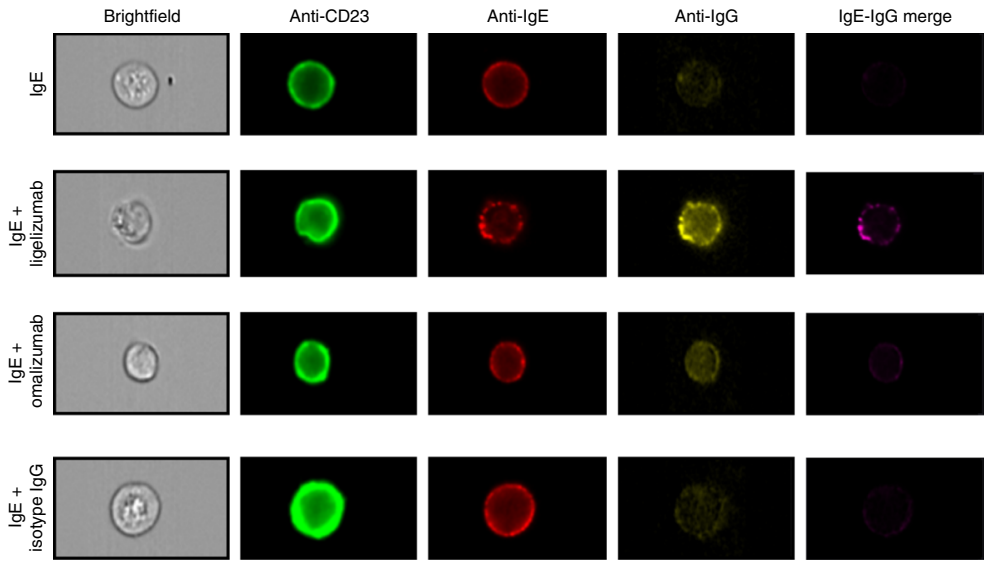

i

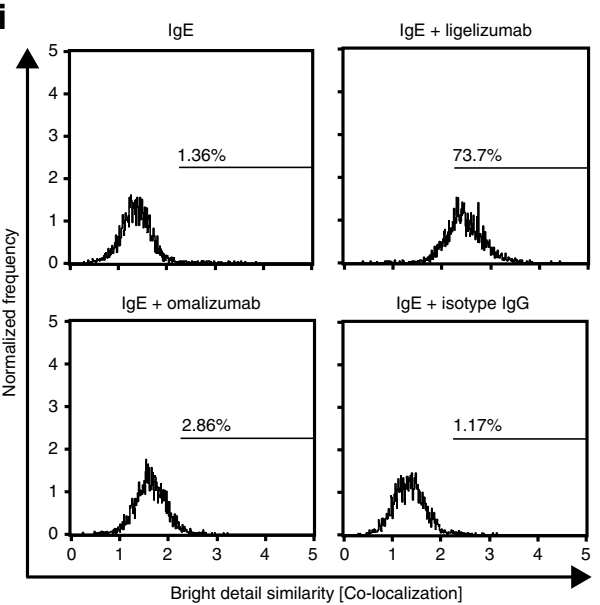

Fig. 4 Binding of CD23:IgE complexes by ligelizumab or omalizumab. a Association and dissociation of IgE to immobilized human recombinant CD23 by SPR. Each color refers to an individual measurement cycle. Curves were fitted (black dashed lines) using a two-state reaction binding model. $\mathbf{b}$ Binding of ligelizumab and omalizumab IgG to CD23 pre-complexed human recombinant IgE was measured by SPR. c Binding of polyclonal anti-lgG to CD23:IgE:antiIgE complexes was assessed by SPR. d Flow cytometric quantification of lgE (d) and lgG (e) surface levels on CD23-expressing RPMI8866 cells after treatment with ligelizumab, omalizumab or isotype IgG with or without blocking of CD23 prior to IgE sensitization (data for technical duplicates are displayed as mean \pm SEM). Representative flow cytometry plots (f) and quantification of IgG-positive RPMI8866 cell frequencies ( $\mathbf{g}$ ) after treatment with ligelizumab or omalizumab with or without blocking of CD23 prior to lgE sensitization (data for technical duplicates are displayed as mean \pm SEM). Representative image stream flow cytometry pictures for CD23-, IgE- and IgG staining (h) and co-localization analysis for lgE- and lgG staining (i) of IgEsensitized RPMI8866 cells after treatment with ligelizumab, omalizumab or isotype IgG. Source data are provided as Source Data file. 
a

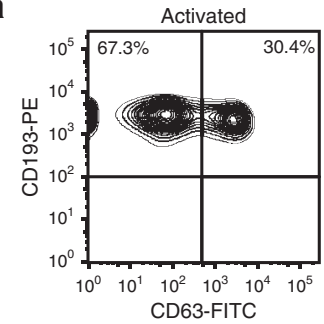

d

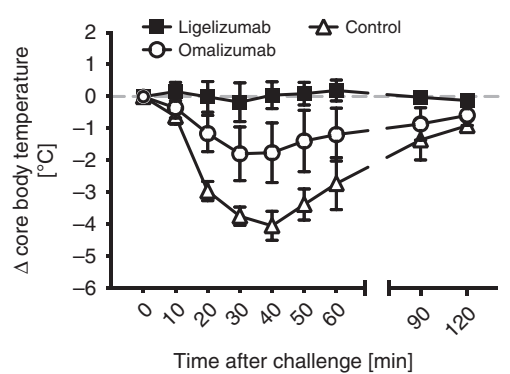

b

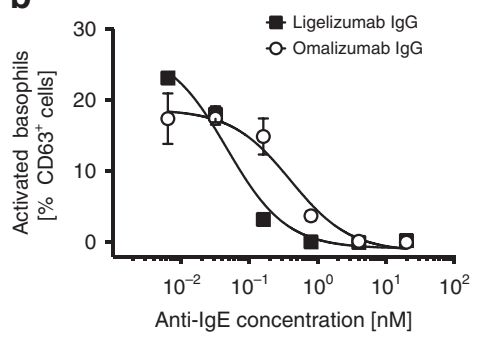

e

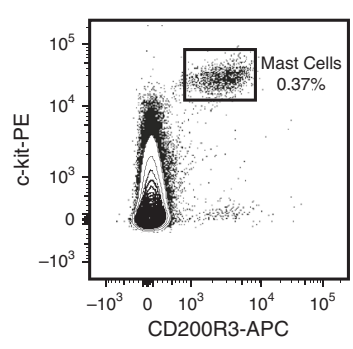

c

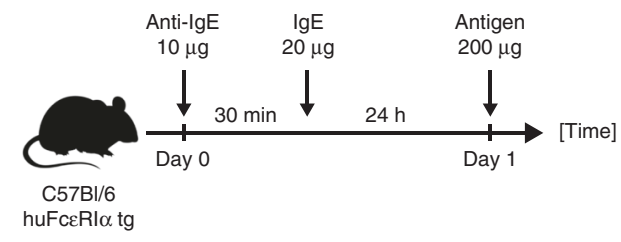

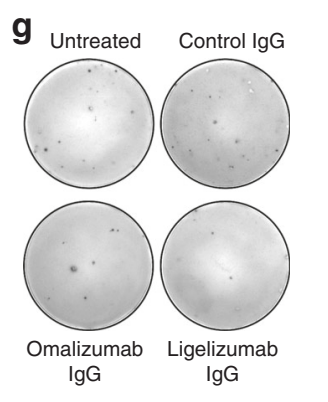

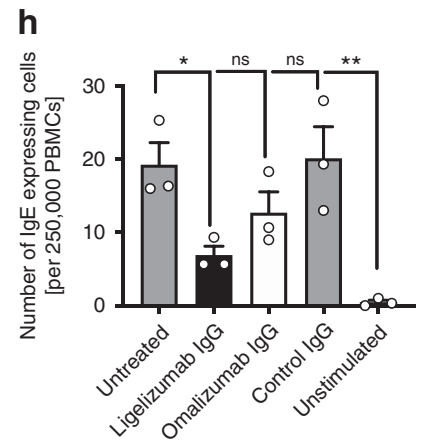

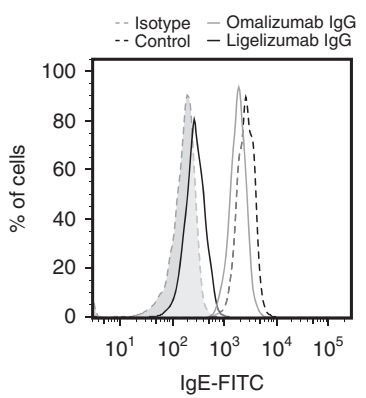

f

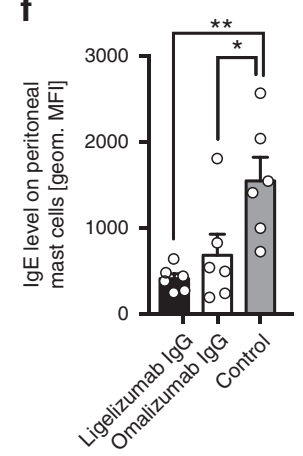

i

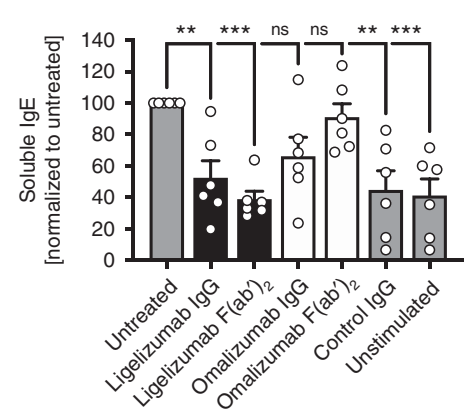

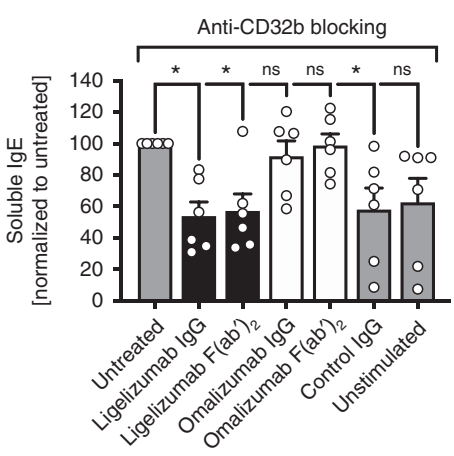

Fig. 5 Inhibition of basophil activation and IgE production of B-cells by ligelizumab or omalizumab. a NIP 7 -BSA-mediated activation of isolated CD193 ${ }^{+}$ primary human basophils resensitized with JW8-IgE using CD63 as degranulation marker by flow cytometry. b Dose-dependent inhibition of primary human basophil activation by pre-incubation of JW8-lgE with increasing concentrations of ligelizumab or omalizumab IgG and subsequent stimulation of the cells with $100 \mathrm{ng} / \mathrm{ml} \mathrm{NIP}_{7}$-BSA. Activation curves for technical duplicates were fitted using a non-linear regression. c Experimental setup for the passive systemic anaphylaxis assay with huFceRl $\alpha$ tg mice. d Changes in body core temperature after antigen challenge for mice treated with ligelizumab, omalizumab or PBS as control ( $n=6$ per group; pooled data from two individual experiments). Representative flow plots (e) and absolute quantification (f) of flow cytometric analysis of peritoneal mast cells after passive systemic anaphylaxis. $\mathbf{g}$ Representative pictures of IgE ELISpots with PBMCs from human donors ( $n=3$ donors) that were stimulated with human recombinant IL-4 and anti-human CD40 antibody in the presence of a control IgG antibody, ligelizumab or omalizumab IgG. h Quantification of the number of IgE expressing cells. i Quantification of soluble IgE in cell culture supernatants of PBMCs from human subjects ( $n=6$ donors) that were stimulated with human recombinant IL- 4 and anti-human CD40 antibody in the presence of ligelizumab $\lg \mathrm{G}$ or $\mathrm{F}\left(\mathrm{ab} \mathrm{b}^{\prime}\right)_{2}$ fragments, omalizumab $\lg \mathrm{G}$ or $\mathrm{F}\left(\mathrm{ab} \mathrm{b}_{2}\right)_{2}$ fragments or a control $\lg \mathrm{G}$ antibody. Data are shown as mean $\pm \mathrm{SEM}$. Different treatments were compared relative to the untreated group using one-way ANOVA with Dunnett's multiple comparison referenced to untreated controls. ${ }^{\star} P<0.05$, ${ }^{\star \star \star} P<0.001$. Source data are provided as Source Data file.

while omalizumab binds such complexes without disrupting them ${ }^{25,41}$. Furthermore, we could show that the interaction of omalizumab with such FceRI-bound $\mathrm{IgE}^{-\mathrm{Fc}_{3-4}}$ fragments on primary human basophils results in a dose-dependent degranulation of the cells. Whether such IgE fragments exist in vivo in certain situations remains to be investigated as well as whether this could potentially explain rare systemic anaphylactic reactions in roughly $0.2 \%$ of omalizumab-treated patients ${ }^{49}$. Ligelizumab lacks the ability to cross-link FceRI $\alpha$-bound IgE- $\mathrm{Fc}_{3-4}$ fragments and it will be interesting to see whether it shows a reduced risk of anaphylaxis and an altered safety profile as compared to omalizumab.

We further observe that omalizumab inhibits IgE-binding to CD23 more potently than ligelizumab, which could potentially play an important role in the inhibition of IgE-mediated antigen presentation and IgE-mediated transport across epithelial barriers ${ }^{12,50}$. It has been shown that allergen-IgE complex-mediated eosinophilic lung inflammation in mice was CD23 dependent ${ }^{48}$. These findings might explain why ligelizumab treatment lacked superior efficacy in phase 2 clinical trials with severe asthma patients compared to placebo and omalizumab (NCT02075008). On the other hand, ligelizumab has the ability to recognize CD23bound IgE on B-cells and decreases IgE production in PBMC cultures. This effect was not mediated by ADCC as $\mathrm{F}\left(\mathrm{ab}^{\prime}\right) 2$ fragments revealed a similar inhibition of IgE production. Our data indicating that ligelizumab downregulates IgE production is in line with the finding that single dose injection of ligelizumab resulted in a significantly longer suppression of free serum IgE 
compared to omalizumab ${ }^{18}$. Further, our results strongly suggest that the mechanism of ligelizumab suppression of IgE synthesis is independent of $\mathrm{F} c \gamma$-receptor engagement but might rather be due to its ability to bind and aggregate CD23:IgE complexes on the surface of B-cells, which has not been observed for omalizumab.

In summary, the structural and mechanistic differences that we have found between ligelizumab and omalizumab may have different impacts on FceRI- and CD23-mediated pathways in patients. Presently, it is concluded that ligelizumab has the potential to be particularly efficacious in diseases driven predominantly by FceRI-dependent reactions, as observed in $\mathrm{CSU}^{31}$.

\section{Methods}

Recombinant proteins and antibodies. Ligelizumab as well as omalizumab antibodies and fragments were produced and kindly provided by Novartis Pharma AG (Basel, Switzerland). Sus11-IgE, JW8-IgE and the anaphylactogenic monoclonal anti-IgE antibody Le27 were purchased from NBS-C BioScience (Vienna, Austria). Monoclonal anti-human CD40 antibody was purchased (Enzo Life Sciences, NY, USA). Recombinant extracellular part of human FceRIa as well as the wild-type $\mathrm{C} 328 \mathrm{IgE}_{-} \mathrm{Fc}_{3-4}$ and the mutated $\mathrm{C} 335 \mathrm{IgE}-\mathrm{Fc}_{3-4}$ were produced in our laboratory ${ }^{36}$. Recombinant human CD23 was purchased (R\&D Systems, Minneapolis, MN, USA). Recombinant human IL-3 and IL-4 were purchased from Peprotec (London, UK). Cells were cultured in $\mathrm{RPMI}^{+/+}$medium composed of RPMI 1640 medium (Biochrome, Cambridge, UK) complemented with $10 \%$ Hyclone FCS (Fisher Scientific, NH, USA), penicillin $100 \mathrm{U} / \mathrm{ml}, 100 \mu \mathrm{g} / \mathrm{ml}$ streptomycin (100× penicillin/streptomycin, Merck, Darmstadt, Germany) and $10 \mathrm{mM}$ HEPES buffer (stock-solution $1 \mathrm{M}$, Life Technologies, CA, USA). For flow cytometry, we used the following antibodies: anti-human IgE FITC (clone Ige21, Thermo Fisher Scientific, MA, USA), monoclonal mouse anti-human FceRIa APC (clone AER-37, Thermo Fisher Scientific, MA, USA) and the appropriate isotype controls monoclonal mouse IgG1, $\kappa$ Isotype control FITC (Thermo Fisher Scientific, MA, USA) and mouse IgG2b Isotype control APC (Thermo Fisher Scientific, MA, USA), monoclonal rat anti-mouse CD200R FITC (clone OX-110, Bio-Rad, CA, USA), monoclonal rat anti-mouse CD117 PE (clone 2B8, Thermo Fisher Scientific, MA, USA), monoclonal mouse anti-human CD19 APC (clone HIB19, BD Bioscience), monoclonal mouse anti-human CD23 FITC and PE (clone EBVCS-5, Biolegend, CA, USA), monoclonal mouse anti-human Ig kappa light chain PE (clone TB28-2, eBioscience, CA, USA). For basophil activation testing, the anti-human CCR3 and anti-human CD63 antibody staining mix from the Flow $\mathrm{CAST}^{\circledast}$ kit was used (Bühlmann Laboratories AG, Schönenbuch, CH).

Expression and purification of IgE:ligelizumab complexes. A scFv codonoptimized construct of ligelizumab was synthesized (Genscript) and cloned into EcoRI/BamHI sites in the pTTVH8G vector for expression in mammalian HEK 293-6E cells (National Research Council, NRC, Canada). The scFv construct consists of the VEGF signal sequence, the ligelizumab VH domain, a GTG $\left(\right.$ GSGGG) ${ }_{3}$ AS linker, the ligelizumab VL domain, a TEV cleavage site and linker to $\mathrm{a} \mathrm{His}_{8}$ tag (MNFLLSWVHWSLA LLLYLHHAKWSQAAPMAEGGGQNQVQLV QSGAEVMKPGSSVKVSCKASGYTFSWYWLEWVRQAPGHGLEWMGEIDPGT FTTNYNEKFKARVTFTADTSTSTAYMELSSLRSEDTAVYYCARFSHFSGSNYD YFDYWGQGTLVTVSSGTGGSGGGGSGGGGSGGGASEIVMTQSPATLSVSPG ERATLSCRASQSIGTNIHWYQQKPGQAPRLLIYYASESISGIPARFSGSGSGTEF TLTISSLQSEDFAVYYCQQSWSWPTTFGGGTKVEIKENLYFQSGGSGHHHHH $\mathrm{HHH}$ ). The wild-type IgE- $\mathrm{Fc}_{3-4}$ with a VGEF signal sequence derived from the pTTVH8G vector was cloned into pYD7 vector (NRC, Canada).

The ligelizumab scFv was co-expressed with the human $\mathrm{IgE}-\mathrm{Fc}_{3-4}$ by $\mathrm{co}^{-}$ transfection in mammalian HEK 293-6E cells. A 1:1 mixture of plasmids was transfected using linear polyethylenimine (PEI), $25 \mathrm{KD}$ (Polysciences) in a DNA: PEI ratio of 1:3. The proteins were expressed for 100-120 h. After harvesting, the cell supernatant was filtered through a $0.45-\mu \mathrm{m}$ filter (Millipore) and incubated overnight at $4{ }^{\circ} \mathrm{C}$ with Ni-NTA resin (Qiagen), washed with wash buffer $(50 \mathrm{mM}$ Tris $\mathrm{pH} 8.0,300 \mathrm{mM} \mathrm{NaCl}, 5 \mathrm{mM}$ imidazole) and eluted with elution buffer (50 mM Tris $\mathrm{pH} 8.0,300 \mathrm{mM} \mathrm{NaCl}, 200 \mathrm{mM}$ imidazole). Eluted protein complex was concentrated using an Amicon Ultra-15 (Millipore) and purified with gel filtration on a Superdex 200 10/300 GL column (GE) using a running buffer consisting of $20 \mathrm{mM}$ Tris $\mathrm{pH} 8.0,150 \mathrm{mM} \mathrm{NaCl}$. His-tags were removed by cleavage with TEV protease in the presence of $2.5 \mathrm{mM}$ BME.

Crystallization and structure determination. Purified $\mathrm{scFv}$ :IgE- $\mathrm{Fc}_{3-4}$ complex was concentrated to a final concentration of $7.3 \mathrm{mg} / \mathrm{ml}$ in $20 \mathrm{mM}$ Tris $\mathrm{pH} 8.0$. Crystallization was carried out using the hanging drop method, with a precipitant composed of $0.2 \mathrm{M} \mathrm{Na}$ thiocyanate $\mathrm{pH} 6.9,20 \%$ PEG3350 and $10 \mathrm{mM}$ spermidine as an additive. Crystals were obtained in $2-5$ days at $14{ }^{\circ} \mathrm{C}$. Crystals were harvested and frozen in $0.2 \mathrm{M}$ Na thiocyanate, $23 \%$ PEG 3350, 25\% glycerol.

A complete diffraction dataset for the complex crystal was collected at $100^{\circ} \mathrm{K}$ at the Advanced Photon Source at Argonne National Laboratories LS-CAT beamline using an X-ray wavelength of $0.979 \AA$. The diffraction data were processed with X-
Ray Detector Software (XDS) ${ }^{51}$. The crystals belong to space group P2 ${ }_{1} 2_{1} 2_{1}$ (Supplementary Table 2). The resolution limit of the data (3.65 $\AA$ ) was set using an $\mathrm{I} /$ sigma value of $1.3 \AA$ and a $\mathrm{CC} 1 / 2$ value of 0.54 . Molecular replacement was carried out with Phenix Phaser ${ }^{52}$ using the structure of the IgE- $\mathrm{Fc}_{2-4}$ (Protein Data Bank code: $2 \mathrm{Y}^{2} \mathrm{Q}^{53}$ ) as a search model for IgE and the scFv structure of the antiCD277 antibody 103.2 (Protein Data Bank code: 4F9P ${ }^{54}$ ) as a search model for ligelizumab. Manual model building was carried out in $\operatorname{Coot}^{55}$ and refinement was done in Phenix Refine ${ }^{52}$ using data from 3.65 to $20.0 \AA$. Model quality was analyzed by Coot, and structure figures were generated using PyMol (Schrodinger, LLC, New York). The final model has Ramachandran statistics of $97.3 \%$ of residues in the preferred region, $2.7 \%$ of the residues in the additionally allowed region and no residues in the disallowed region. Additional refinement statistics are collected in Supplementary Table 2.

Protein interaction measurements with SPR. All SPR measurements were carried out on a GE Healthcare Biacore X100 device (IL, USA). HBS-EP ${ }^{+}$was used as running buffer at a flowrate of $10 \mu \mathrm{l} / \mathrm{min}$. The target proteins were immobilized on flow cell 2 ( $\mathrm{Fc} 2)$ of a CM5 sensor chip by standard amine coupling. The sensorgrams reflect binding responses on $\mathrm{Fc} 2$ minus binding responses on the reference Fcl. To determine binding kinetics, we used the BIAevaluation software. Affinity constants were calculated using a 1:1 langmuir curve fitting model.

To determine binding kinetics of ligelizumab and omalizumab antibodies/ fragments for human full-length IgE, $3000 \mathrm{RU}$ of the anti-IgE Le27 were immobilized on flow cell 2 at $\mathrm{pH} 4.0$. A concentration of $30 \mathrm{nM}$ Sus11-IgE was subsequently captured for $120 \mathrm{~s}$ to reach a response of $\sim 100 \mathrm{RU}$. Various concentrations (1.56-25 nM) of ligelizumab and omalizumab antibodies/fragments were injected for $120 \mathrm{~s}$ and the dissociation was measured for $240 \mathrm{~s}$ under constant buffer flow. After each run, the chip surface was regenerated with $50 \mathrm{mM} \mathrm{NaOH}$ and reloaded with Sus11-IgE.

To determine binding kinetics of ligelizumab and omalizumab IgG for wildtype $\mathrm{C} 328$ and mutated $\mathrm{C} 335 \mathrm{IgE}-\mathrm{Fc}_{3-4}$ variants, $100 \mathrm{RU}$ of ligelizumab or omalizumab IgG were immobilized on individual chips (ligelizumab: $\mathrm{pH}$ 5.0, omalizumab: $\mathrm{pH} 4.5)$. A blank immobilization was performed on flow cell 1 . Different concentrations $(0.3-5 \mathrm{nM})$ of C328 and C335 IgE-Fc $3-4$ were injected for $120 \mathrm{~s}$ and the dissociation was measured for $180 \mathrm{~s}$ under constant buffer flow. After each run, the chip surface was regenerated with $10 \mathrm{mM}$ glycine- $\mathrm{HCl} \mathrm{pH} \mathrm{2.0.}$

To assess whether ligelizumab or omalizumab IgG recognize FceRIa:IgE complexes, $1000 \mathrm{RU}$ of recombinant human FceRIa was immobilized on flow cell 2 at $\mathrm{pH}$ 4.0. A blank immobilization was performed on flow cell 1. A concentration of $20 \mathrm{nM}$ Sus11-IgE was subsequently captured for $120 \mathrm{~s}$ to reach a response of $>100$ RU. Various concentrations (3.13-100 nM) of ligelizumab, omalizumab antibodies/fragments and Le27 were injected for $120 \mathrm{~s}$ and the dissociation was measured for $180 \mathrm{~s}$ under constant buffer flow. After each run, the chip surface was regenerated with $50 \mathrm{mM} \mathrm{NaOH}$ and reloaded with Sus11-IgE.

To assess whether ligelizumab or omalizumab IgG may disrupt FceRIa:IgE complexes, 1000 RU of recombinant human FceRIa was immobilized on flow cell 2 at $\mathrm{pH}$ 4.0. A blank immobilization was performed on flow cell 1. A concentration of $20 \mathrm{nM}$ Sus11-IgE was subsequently captured for $120 \mathrm{~s}$ to reach a response $>100$ RU. Three concentrations $(0.25,0.5$ and $1 \mu \mathrm{M})$ of ligelizumab or omalizumab antibodies/fragments were injected for 42 times $540 \mathrm{~s}$ with a dissociation time of $180 \mathrm{~s}$ between each injection under constant buffer flow. At the end of each run the chip surface was regenerated with $50 \mathrm{mM} \mathrm{NaOH}$ and reloaded with Sus11-IgE.

To assess whether ligelizumab or omalizumab IgG may disrupt FceRIa:IgE-Fc complexes, $1000 \mathrm{RU}$ of recombinant human FceRIa was immobilized on flow cell 2 at $\mathrm{pH}$ 4.0. A blank immobilization was performed on flow cell 1. A concentration of $20 \mathrm{nM}$ IgE- $\mathrm{FC}_{3-4}$ was subsequently captured for $120 \mathrm{~s}$ to reach a response $>100 \mathrm{RU}$. Various concentrations (3.13-100 $\mathrm{nM}$ ) of ligelizumab, omalizumab antibodies/ fragments and Le27 were injected for $120 \mathrm{~s}$ and the dissociation was measured for $180 \mathrm{~s}$ under constant buffer flow. After each run, the chip surface was regenerated with $50 \mathrm{mM} \mathrm{NaOH}$ and reloaded with $\mathrm{IgE}-\mathrm{Fc}_{3-4}$.

To assess whether ligelizumab or omalizumab IgG interact with CD23:IgE complexes, 3000 RU of recombinant human CD23 was immobilized on flow cell 2 at $\mathrm{pH}$ 4.0. A blank immobilization was performed on flow cell 1. A concentration of $125 \mathrm{nM}$ JW8-IgE was captured for $120 \mathrm{~s}$ to reach a response $>100$ RU. Various concentrations (31.25-500 nM) of ligelizumab, omalizumab antibodies were injected for $120 \mathrm{~s}$ and the dissociation was measured for $180 \mathrm{~s}$ under constant buffer flow. After each run, the chip surface was regenerated with $50 \mathrm{mM} \mathrm{NaOH}$ and reloaded with JW8-IgE. Ligelizumab and omalizumab IgG binding to preformed CD23:IgE complexes was assessed using a polyclonal sheep anti-human IgG antibody at $125 \mathrm{nM}$ concentration (The Binding Site, Birmingham, UK).

Protein interaction measurements with ELISA. To measure the binding interaction of ligelizumab or omalizumab with human $\operatorname{IgE}$, the anti-IgE antibodies were immobilized on plastic surface of a 96-half-well plate (Corning, NY, USA) at a concentration of $30 \mathrm{nM}$ by overnight incubation in PBS at $4{ }^{\circ} \mathrm{C}$. The next day, the plate was blocked with PBS $/ 0.15 \%$ casein for $2 \mathrm{~h}$ at room temperature (RT) and washed with PBS/0.05\% Tween. Human Sus11-IgE was incubated at a serial dilution $(0.03-7.5 \mathrm{nM})$ for $1 \mathrm{~h}$ at RT. The plate was washed two times with PBS/ $0.05 \%$ Tween and incubated for $1 \mathrm{~h}$ with the same wash buffer followed by three times washing with PBS only. IgE was detected with monoclonal non-competitive 
anti-IgE Le27 coupled to horseradish-peroxidase (HRP). TMB (3,3',5,5'-tetramethylbenzidine, Merck, Darmstadt, Germany) was used as a substrate for HRP and the reaction was stopped with $1 \mathrm{M}$ sulfuric acid. Absorbance was measured at $450 \mathrm{~nm}$ wavelength using the standard ELISA reader SpectraMax M5 from Molecular Device LLC (San Jose, CA, USA).

To measure the binding interaction of ligelizumab or omalizumab with wildtype $\mathrm{C} 328$ and mutated $\mathrm{C} 335 \mathrm{IgE}-\mathrm{Fc}_{3-4}$ variants, the anti-IgE antibodies were immobilized on plastic surface of a 96-half-well plate (Corning, NY, USA) at a concentration of $10 \mathrm{nM}$ by overnight incubation in PBS at $4{ }^{\circ} \mathrm{C}$. The next day, the plate was blocked with $\mathrm{PBS} / 0.15 \%$ casein for $2 \mathrm{~h}$ at RT and washed with $\mathrm{PBS} / 0.05 \%$ Tween. Wild-type C328 and mutated $\mathrm{C} 335 \mathrm{IgE}_{-} \mathrm{FC}_{3-4}$ variants were incubated at a serial dilution $(0.0001-10 \mathrm{nM})$ for $1 \mathrm{~h}$ at RT and subsequently washed with PBS/ $0.05 \%$ Tween and PBS. Development of the assay was performed as mentioned above.

To measure IgE-binding to FceRI, we immobilized recombinant human FceRIa on a plastic surface of a 96-half-well plate (Corning, NY, USA) at $30 \mathrm{nM}$ by overnight incubation in PBS at $4{ }^{\circ} \mathrm{C}$. The next day, the plate was blocked with PBS/ $0.15 \%$ casein for $2 \mathrm{~h}$ at RT. Biotinylated JW8-IgE was incubatd at a 1:3 serial dilution $(60-0.001 \mathrm{nM})$ for $1 \mathrm{~h}$ at RT. IgE-binding was detected with poly-HRPconjugated streptavidin (Thermo Scientific, Waltham, MA, USA) and was followed by development with TMB.

To assess the inhibition of IgE-binding to FceRIa by ligelizumab and omalizumab, we immobilized recombinant human FceRIa on plastic surface of a 96-half-well plate (Corning, NY, USA) at a concentration of $30 \mathrm{nM}$ by overnight incubation in PBS at $4{ }^{\circ} \mathrm{C}$. The next day, the plate was blocked with $\mathrm{PBS} / 0.15 \%$ casein. Anti-IgE antibodies $(0.0078-600 \mathrm{nM})$ were pre-incubated with biotinylated JW8-IgE $(0.78 \mathrm{nM})$ for $30 \mathrm{~min}$ at RT and were added for $1 \mathrm{~h}$ to the plate. The plate was washed with PBS/0.05\% Tween and PBS. IgE binding was detected with polyHRP-conjugated streptavidin and was followed by development with TMB.

For the CD23-binding ELISA, we immobilized $60 \mathrm{nM}$ recombinant human CD23 (R\&D Systems, Minneapolis, MA, USA) on a 96-half-well plate (Corning, NY, USA) by overnight incubation at $4{ }^{\circ} \mathrm{C}$. The following day, the plate was blocked with $\mathrm{PBS} / 0.15 \%$ casein. The JW8-IgE was mixed 1:1 with $\mathrm{NIP}_{7}-\mathrm{BSA}$ (Biosearch Technologies, Petaluma, CA, USA) in PBS/0.15\% casein at a 1:2 serial dilution $(280-2.1875 \mathrm{nM})$ and incubated for $30 \mathrm{~min}$ at RT. The IgE-antigen complexes were then incubated on the plate for $1 \mathrm{~h}$ at RT. IgE binding was detected with biotinylated anti-IgE antibody Le27 $(2.66 \mu \mathrm{g} / \mathrm{ml})$ and poly-HRP-conjugated streptavidin followed by development with TMB. In the inhibition ELISA for CD23-binding IgE-antigen complexes $(70 \mathrm{nM}: 70 \mathrm{nM})$ were incubated with a $1: 2$ serial dilution of the anti-IgE antibodies $(280-0.5469 \mathrm{nM})$ for $30 \mathrm{~min}$ at RT before incubation on the ELISA plate.

Protein interaction measurements on cells. Primary human basophils and $\mathrm{BDCA}^{+}$DCs were isolated from whole-blood donations. Human peripheral whole-blood was obtained from volunteering donors, who provided informed consent in accordance with the Helsinki Declaration. The study was approved by the local ethics committee (KEK 2018-00204). Basophils and BDCA1 ${ }^{+}$DCs were enriched by Percoll density centrifugation of dextran-sedimented supernatants. Furthermore, basophils were purified with negative selection using the Milteny basophil isolation kit II (Miltenyi Biotec, Bergisch Gladbach, Germany). $\mathrm{BDCA1}^{+}$DCs were isolated with positive selection using the Milteny human CD1s (BDCA-1 ${ }^{+}$dendritic cell isolation kit (Miltenyi Biotec, Bergisch)). Cells were analyzed for purity via flow cytometry.

To compare the efficacy of ligelizumab and omalizumab IgG to inhibit IgE binding to FceRIa expressing cells, we cultured isolated primary human basophils at a density of $1 \times 10^{6}$ cells $/ \mathrm{ml}$ per well in a 96-well round-bottom plate (Falcon, Tewksbury, MA, USA). First, we removed endogenous IgE from the cell surface by addition of $5 \mu \mathrm{M}$ of the disruptive anti-IgE DARPin ${ }^{\circ}$ protein bi53_79 in $\mathrm{RPMI}^{+/+}$ supplemented with $10 \mathrm{ng} / \mathrm{ml}$ recombinant human IL-3 overnight for basophils. The next day, the cells were washed and incubated with different concentrations of JW8- $\operatorname{IgE}(0.006-100 \mathrm{nM})$ to assess dose-dependent binding. The concentration of $2 \mathrm{nM}$ was further used for inhibition experiments with anti-IgE antibodies. JW8IgE was pre-incubated with increasing concentrations $(0.032-100 \mathrm{nM})$ of ligelizumab or omalizumab for $30 \mathrm{~min}$ at RT. Surface IgE was stained and quantified by flow cytometry $1 \mathrm{~h}$ after adding this mix to the cells. To assess the inhibition profile of ligelizumab and omalizumab IgG to inhibit IgE binding to FceRIa BDCA-1 ${ }^{+}$DCs without the presence of any additionally cytokines or growth factors, we modified the protocol above and removed the endogenouse IgE from the cells by the disruptive anti-IgE DARPin ${ }^{\circledR}$ protein bi53_79 only in $\mathrm{RPMI}^{+/+}$medium during an incubation of $4 \mathrm{~h}$. Subsequently, the cells were washed and incubated with different concentrations of JW8- $\operatorname{IgE}(100-0.005 \mathrm{nM})$ to assess dose-dependent binding. The concentration of $25 \mathrm{nM}$ JW8-IgE was further used for inhibition experiments with anti-IgE antibodies. JW8-IgE was preincubated with increasing concentrations $(0.0012-312.5 \mathrm{nM})$ of ligelizumab or omalizumab for $30 \mathrm{~min}$ at RT. Surface IgE was stained and quantified by flow cytometry $1 \mathrm{~h}$ after adding this mix to the cells. Surface $\operatorname{IgE}$ was stained and quantified by flow cytometry $1 \mathrm{~h}$ after adding this mix to the cells.

To assess inhibition of IgE-dependent basophil activation, we first determined the concentration of JW8-IgE to be used to reach half-maximal activation. For this we titrated JW8-IgE $(0.0064-20 \mathrm{nM})$ on 25,000 anti-IgE DARPin ${ }^{6}$ protein-treated human primary basophils and subsequently stimulated these cells with $100 \mathrm{ng} / \mathrm{mL}$ $\mathrm{NIP}_{7}$-BSA (Biosearch Technologies, Petaluma, CA, USA) in $\mathrm{RPMI}^{+/+}$-containing human $10 \mathrm{ng} / \mathrm{ml}$ recombinant human IL-3 and Flow CAST ${ }^{\oplus}$ kit antibody staining mix (Bühlmann Laboratories AG, Schönenbuch, $\mathrm{CH}$ ). The concentration of 0.68 $\mathrm{nM}$ JW8-IgE was subsequently used for pre-incubation with increasing concentrations $(0.0064-20 \mathrm{nM})$ of ligelizumab and omalizumab in $\mathrm{RPMI}^{+/+}$ medium for $30 \mathrm{~min}$ at RT. Anti-IgE DARPin protein-treated primary human basophils were then sensitized for $2 \mathrm{~h}$ at $37^{\circ} \mathrm{C}$ with this mixture and stimulated with $100 \mathrm{ng} / \mathrm{mL} \mathrm{NIP}_{7}$-BSA. Activation was determined by measuring $\mathrm{CD}^{+} 3^{+}$ basophils using flow cytometry.

To investigate whether anti-IgE antibodies might actively remove FceRIabound IgE from the cell surface, we cultured 50,000 isolated primary human basophils $\left(1 \times 10^{6}\right.$ cells $\left./ \mathrm{ml}\right)$ with either $0,0.25,0.5$ or $1 \mu \mathrm{M}$ of ligelizumab or omalizumab antibodies/fragments in $\mathrm{RPMI}^{+/+}$supplemented with $10 \mathrm{ng} / \mathrm{ml}$ recombinant human IL-3. After 3 and 6 days of culture, the cells were stained with anti-IgE antibody for $15 \mathrm{~min}$ at RT and measured by flow cytometry.

The human RPMI8866 leukemia B-cell line was kindly provided by Dr. Monique Vogel. The cells were cultured in $\mathrm{RPMI}^{+/+}$medium at a density of $2.5 \times$ $10^{5} \mathrm{cell} / \mathrm{s} / \mathrm{ml}$ in a $250-\mathrm{ml}$ cell culture flask (Greiner Bio One, Kremsmünster, AUT). One day before the experiment, the cells were split 1:2 in $\mathrm{RPMI}^{+/+}$medium. Flow cytometry was performed using a BD FACSCanto device (BD Bioscience, Franklin Lakes, NJ, USA) and results were evaluated with FlowJo Version 10.1 (Ashland, OR, USA).

To assess whether ligelizumab accelerates dissociation of $\mathrm{F}_{\mathrm{c} \varepsilon \mathrm{RI}}$-bound IgE- $\mathrm{Fc}_{3-4}$ on purified primary human basophils (purity $>90 \%$ ), endogenous IgE was removed from 50,000 basophils per well by incubation with $5 \mu \mathrm{M}$ disruptive anti-IgE DARPin protein bi53_79 in $\mathrm{RPMI}^{+/+}$. After washing with PBS pH 7.4, the cells were reloaded with $100 \mathrm{nM} \mathrm{JW8}-\mathrm{IgE}$ or $\mathrm{C} 328 \mathrm{IgE}-\mathrm{Fc}_{3-4}$. Again the cells were washed with PBS pH 7.4. Then the cells were treated with 0.6-66.6 nM ligelizumab or omalizumab IgG in $\mathrm{RPMI}^{+/+}$medium containing human $10 \mathrm{ng} / \mathrm{ml}$ recombinant human IL-3 for $30 \mathrm{~min}$ at $37^{\circ} \mathrm{C}$ and $5 \% \mathrm{CO}_{2}$. Surface expression of human IgE was determined with an anti-human IgE FITC antibody and basophil activation was assessed using the Flow CAST $^{\oplus}$ kit (Bühlmann Laboratories AG) by flow cytometry.

For IgE titration on CD23 expressing cells, $5 \times 10^{4}$ RPMI8866 cells per well were seeded in a 96-well plate (Corning, NY, USA) and incubated with biotinylated JW8-IgE for $1 \mathrm{~h}$ at $37^{\circ} \mathrm{C}, 5 \% \mathrm{CO}_{2}$ in $\mathrm{RPMI}^{+/+}$medium. Subsequently, the cells were stained with streptavidin FITC (Invitrogen, Carlsbad, CA, USA), anti-CD23 and anti-CD19 antibodies for $20 \mathrm{~min}$ at $4{ }^{\circ} \mathrm{C}$. For the IgE inhibition on $\mathrm{CD} 23$ expressing cells, $12.5 \mathrm{nM}$ biotinylated JW8-IgE was pre-complexed with the antiIgE antibodies $\left(0.01-25 \mathrm{nM}, 1: 2\right.$ serial dilution) in $\mathrm{RPMI}^{+/+}$medium for $30 \mathrm{~min}$ at RT. Subsequently, this mix was added to the RPMI8866 cells for $1 \mathrm{~h}$ at $37^{\circ} \mathrm{C}, 5 \%$ $\mathrm{CO}_{2}$ in $\mathrm{RPMI}^{+/+}$medium. Staining was performed as mentioned above.

To check for binding of anti-IgE antibodies to CD23-bound IgE RPMI8866 cells were incubated with $12.5 \mathrm{nM}$ biotinylated JW8-IgE for $1 \mathrm{~h}$ at $37^{\circ} \mathrm{C}, 5 \% \mathrm{CO}_{2}$ in $\mathrm{RPMI}^{+/+}$medium. The cells were then washed three times with $150 \mu \mathrm{l}$ of PBS pH 7.4 and centrifuged at $600 \times g$ for $5 \mathrm{~min}$ at $4{ }^{\circ} \mathrm{C}$, resuspended in $\mathrm{RPMI}^{+/+}$medium containing $12.5 \mathrm{nM}$ ligelizumab, omalizumab or control IgG and incubated for 30 min at $37^{\circ} \mathrm{C}$. Subsequently, the cells were washed two times with $200 \mu \mathrm{l}$ of PBS pH 7.4 and stained with streptavidin, anti-CD19 and monoclonal mouse anti-human Ig $\kappa$ light chain (clone TB28-2, Thermo Fisher Scientific, MA, USA) at $4{ }^{\circ} \mathrm{C}$. Blocking of $\mathrm{CD} 23$ receptor was performed by incubation of the RPMI 8866 cells with $5 \mathrm{nM}$ anti-CD23 DARPin ${ }^{\oplus}$ protein D89_86 (ref. ${ }^{44}$ ) for $15 \mathrm{~min}$ at $37^{\circ} \mathrm{C}, 5 \%$ $\mathrm{CO}_{2}$. Cells were then washed once with PBS before incubation with JW8-IgE and the anti-IgE antibodies as described above.

To assess the effect of ligelizumab and omalizumab on IgE:antigen complex internalization with $\mathrm{BDCA1}^{+} \mathrm{DCs}$, we conjugated $\mathrm{pH}$-sensitive rodamine $(\mathrm{pH}-$ Rodo) to NIP-specific JW8 IgE by the pHrodo Red Microscale Labeling Kit (Life Technologies). The fluorophore $\mathrm{pH}$-Rodo increases emission at more acidic $\mathrm{pH}$ ), which happens along the pathway of endocytosis/phagocytosis (i.e. endosomal/ lysosomal $\mathrm{pH}$ range from $\mathrm{pH} 6$ to 4.5). First $\mathrm{pH}$-Rodo IgE:antigen complexes were formulated with $25 \mathrm{nM} \mathrm{pH}$-rodo IgE and $2.5 \mathrm{nM}$ NIP(15)BSA (Biosearch Technologies, Petaluma, California, USA) for $0.5 \mathrm{~h}$ at RT and were then supplemented with an $5 \mathrm{nM}$ ligelizumab or omalizumab for additional $0.5 \mathrm{~h}$ at RT Upon removing the endogenous IgE from basophils and $\mathrm{BDCA}^{+}{ }^{+} \mathrm{DCs}$ by the disruptive anti-IgE DARPin ${ }^{\circledast}$ protein bi53_79 for $4 \mathrm{~h}$ at $37^{\circ} \mathrm{C}$, the cells were washed and pulsed with formulated IgE:antigen:anti-IgE antigen complexes for $2 \mathrm{~h}$ at $37^{\circ} \mathrm{C}$. After pulsing the cells, the cells were washed intensively and further incubated time-dependently (i.e. $4 \mathrm{~h}, 8 \mathrm{~h}, 12 \mathrm{~h}, 16 \mathrm{~h}$ ) at $37^{\circ} \mathrm{C}$. The pH-Rodo JW8IgE emissions were finally measured in the PE-channel by flow-cytometry.

To assess the binding of anti-IgE antibodies to CD23-bound IgE by multispectral imaging flow cytometry, RPMI8866 cells were diluted to $1 \times 10^{6}$ cells/ $\mathrm{ml}$, and $1 \times 10^{5}$ cells per well were seeded in a 96-well round-bottom plate. Washing was performed once with $200 \mu \mathrm{l}$ of PBS pH 7.4 at $500 \times g$ for $5 \mathrm{~min}$ at $4{ }^{\circ} \mathrm{C}$. The cells were then resuspended in $100 \mu \mathrm{l}$ of $\mathrm{RPMI}^{+/+}$medium containing $12.5 \mathrm{nM}$ biotinylated JW8-IgE and incubated for $1 \mathrm{~h}$ at $37^{\circ} \mathrm{C}, 5 \% \mathrm{CO}_{2}$. Afterward, the cells were washed three times with $200 \mu \mathrm{l}$ of PBS pH 7.4 at $500 \times g$ for $5 \mathrm{~min}$ at $4{ }^{\circ} \mathrm{C}$, followed by $30 \mathrm{~min}$ incubation at $37^{\circ} \mathrm{C}, 5 \% \mathrm{CO}_{2}$ in $100 \mu$ of $\mathrm{RPMI}^{+/+}$ medium containing $12.5 \mathrm{nM}$ ligelizumab, omalizumab or isotype IgG. Subsequently, the cells were stained with anti-CD23, anti-Ig $\kappa$ light chain and streptavidin antibodies for $20 \mathrm{~min}$ at $4^{\circ} \mathrm{C}$. Binding of IgE and the anti-IgE 
antibodies was assessed using an Amnis ${ }^{\circledR}$ ImageStream ${ }^{\circledR} \mathrm{X}$ MKII and the corresponding IDEAS ${ }^{\circledast}$ software (Luminex corporation, Austin, TX, USA).

IgE ELISpot and culture supernatants. Peripheral blood mononuclear cells were isolated from fresh whole blood supplemented with 100 mM EDTA using Ficoll Paque PLUS (GE Healthcare, Chicago, IL, USA) density gradient centrifugation. The blood was diluted 1:2 in PBMC wash buffer (PBS pH 7.4 complemented with $2 \%$ FCS, 2 mM EDTA), overlaid onto Ficoll layer and centrifuged at $1800 \mathrm{rpm}$ for $35 \mathrm{~min}$ at RT with brakes off. The peripheral blood leukocyte (PBL) layer was extracted and washed with PBMC wash buffer at $1200 \mathrm{rpm}$ for $5 \mathrm{~min}$, followed by two times washing with PBS pH 7.4 at $1000 \mathrm{rpm}$ for $10 \mathrm{~min}$.

A total of $2.5 \times 10^{5}$ PBMCs were cultured in 96 -well round-bottom plates at a density of $1 \times 10^{6}$ cells $/ \mathrm{ml}$ in $\mathrm{RPMI}^{+/+}$medium. The cells were stimulated with 30 $\mathrm{ng} / \mathrm{ml} \mathrm{recombinant} \mathrm{human} \mathrm{IL} 4$ and $1 \mu \mathrm{g} / \mathrm{ml}$ anti-human CD40 antibody for 6 days at $37^{\circ} \mathrm{C}, 5 \% \mathrm{CO}_{2}$ in the presence of $0.5 \mu \mathrm{M}$ anti-IgE antibodies. Unstimulated, untreated and monoclonal anti-human IgG1 antibody-treated cells served as controls. For the detection of IgE-producing B-cells, we used 96-well MultiScreen filter plates (Merck Milipore, Burlington, MA, USA) and the human IgE ELISpotBASIC kit (Mabtech, Nacka Strand, Sweden). Overnight incubation of the coating antibody $(15 \mu \mathrm{g} / \mathrm{ml})$ at $4{ }^{\circ} \mathrm{C}$ was followed by blocking for $2 \mathrm{~h}$ with $\mathrm{RPMI}^{+/+}$ medium the next day. The PBMCs were washed twice with PBS pH 7.4 before transfer to a MultiScreen plate and incubation in $\mathrm{RPMI}^{+/+}$medium complemented with recombinant human IL-4 $(30 \mathrm{ng} / \mathrm{ml})$ and anti-CD40 $(1 \mu \mathrm{g} / \mathrm{ml})$ for 24 hours at $37^{\circ} \mathrm{C}, 5 \% \mathrm{CO}_{2}$. For IgE detection, Mabtech detection antibody mixture $(1 \mu \mathrm{g} / \mathrm{ml}$, $5 \mathrm{~h})$ and poly-HRP-conjugated streptavidin $(0.17 \mu \mathrm{g} / \mathrm{ml}, 30 \mathrm{~min})$ were diluted in $\mathrm{RPMI}^{+/+}$medium and incubated on ELISA plate shaker at RT. For HRP substrate, we used the AEC staining kit (Sigma, Kawasaki, Kanagawa, Japan) and incubated the plate with $50 \mu \mathrm{l}$ per well for $5 \mathrm{~min}$. The colorimetric reaction was stopped by washing the plate with ddH2O. Washing steps were performed with $\mathrm{PBS} \mathrm{pH} 7.4$ or PBS pH 7.4/0.05\% Tween. Spots were quantified using an ELISpot reader and the corresponding iSpot software v7.0 (AID GmbH, Strassberg, Germany).

To assess the effect of anti-IgE antibodies on the production of soluble IgE, we cultured PBMCs at $1 \times 10^{6} \mathrm{cells} / \mathrm{ml}$ in $\mathrm{RPMI}^{+/+}$medium at $37^{\circ} \mathrm{C}, 5 \% \mathrm{CO}_{2}$ in the presence of $0.5 \mu \mathrm{M}$ anti-IgE antibodies and $0.5 \mu \mathrm{M}$ of the anti-Fc $\gamma$ RIIB DARPin ${ }^{\oplus}$ protein D11 (ref. ${ }^{56}$ ), respectively. IgE production was induced by stimulation with $30 \mathrm{ng} / \mathrm{ml}$ recombinant human IL-4 and $1 \mu \mathrm{g} / \mathrm{ml}$ anti-human CD40 antibody for 12 days. On day 12, the supernatants were collected and soluble IgE was measured by ELISA. For the ELISA, anti-IgE antibody Le27 was immobilized on plastic surface of a 96-half-well plate (Corning, NY, USA) at a concentration of $30 \mathrm{nM}$ by overnight incubation in PBS at $4{ }^{\circ} \mathrm{C}$. The next day, the plate was blocked with PBS/ $0.15 \%$ casein. The culture supernatants were incubated for $1 \mathrm{~h}$ on the plate followed by washing twice with PBS pH 7.4 or PBS pH 7.4/0.05\% Tween. IgE was detected using Mabtech detection antibody mixture $(1 \mu \mathrm{g} / \mathrm{ml}, 1$ hour $)$ and poly-HRPconjugated streptavidin $(0.17 \mu \mathrm{g} / \mathrm{ml}, 30 \mathrm{~min})$ diluted in $\mathrm{PBS} / 0.15 \%$ casein and incubated on ELISA plate shaker at RT. TMB (Merck, Darmstadt, Germany) was used as a substrate for HRP and the reaction was stopped with $1 \mathrm{M}$ sulfuric acid. Absorbance was measured at $450 \mathrm{~nm}$ wavelength using the standard ELISA reader SpectraMax M5 from Molecular Device LLC (San Jose, CA, USA).

In vivo passive systemic anaphylaxis. Mice transgenic for human FceRIa (huFceRIa tg) on a mixed C57BL/6J-C57BL/6N background were obtained from Prof. J.-P. Kinet. All animal experimentation was approved by the local ethics committee (authorization BE66/18). Seven days before the experiment, huFceRIa tg mice were subcutaneously implanted with an electronic temperature transponder (IPTT-300) from BMDS (Delaware, USA) to measure body-core temperature as instructed by the manufacturer. On day 0 , mice received an intraperitoneal injection of PBS or $20 \mu \mathrm{g}$ of anti-IgE antibody (ligelizumab or omalizumab in $200 \mu \mathrm{l}$ ). Half an hour later, mice were passively sensitized with $20 \mu \mathrm{g}$ of NIP-specific human JW8-IgE (in $200 \mu \mathrm{l}$ ) by intraperitoneal injection. On day 1, mice were challenged by intraperitoneal injection of $200 \mu \mathrm{g}$ of $\mathrm{NIP}_{20}$-BSA (Biosearch Technologies, Petaluma, CA, USA). Body-core temperature was measured before challenge (baseline) and every $10 \mathrm{~min}$ after antigen-challenge for $60 \mathrm{~min}$ and every $30 \mathrm{~min}$ until $120 \mathrm{~min}$. Data are represented as measured temperature after challenge minus baseline temperature ( $\Delta$ core body temperature) for each time point.

Reporting summary. Further information on research design is available in the Nature Research Reporting Summary linked to this article.

\section{Data availability}

Coordinates of the IgE-Fc:ligelizumab-scFv complex structure have been deposited to the Protein Data Bank (PDB) under accession number 6UQR (https://doi.org/10.2210/ pdb6uqr/pdb). Structural information about FceRIa:IgE-Fc $2-4$ (PDB ID: 2Y7Q (https:// doi.org/10.2210/pdb2Y7Q/pdb) ${ }^{53}$ ), CD23:IgE-Fc $2-4$ (PDB ID: 4EZM (https://doi.org/ $10.2210 / \mathrm{pdb} 4 \mathrm{EZM} / \mathrm{pdb})^{57}$ ) and Omalizumab-Fab:IgE-Fc ${ }_{3-4}$ (PDB ID: 5HYS (https://doi. org/10.2210/pdb5HYS/pdb) ${ }^{41}$ ) complexes are accessible in the Protein Data Bank (PDB). Raw data for Figs. 1, 2, 3, 4, 5, and Supplementary Figs. 1, 2, 3, 5 are provided in the Source Data file. All other data are available from the corresponding authors upon request.
Received: 14 May 2019; Accepted: 30 November 2019; Published online: 08 January 2020

\section{References}

1. Gasser, P. \& Eggel, A. Targeting IgE in allergic disease. Curr. Opin. Immunol. 54, 86-92 (2018).

2. Balbino, B., Conde, E., Marichal, T., Starkl, P. \& Reber, L. L. Approaches to target IgE antibodies in allergic diseases. Pharmacol. Ther. 191, 50-64 (2018).

3. Heusser, C. \& Jardieu, P. Therapeutic potential of anti-IgE antibodies. Curr. Opin. Immunol. 9, 805-813 (1997).

4. Sutton, B. J. \& Davies, A. M. Structure and dynamics of IgE-receptor interactions: FceRI and CD23/FceRII. Immunol. Rev. 268, 222-235 (2015).

5. Gould, H. J. \& Sutton, B. J. IgE in allergy and asthma today. Nat. Rev. Immunol. 8, 205-217 (2008).

6. Garman, S. C., Wurzburg, B. A., Tarchevskaya, S. S., Kinet, J. P. \& Jardetzky, T. S. Structure of the Fc fragment of human IgE bound to its high-affinity receptor Fc epsilonRI alpha. Nature 406, 259-266 (2000).

7. Hunt, J. et al. A fluorescent biosensor reveals conformational changes in human immunoglobulin E Fc: implications for mechanisms of receptor binding, inhibition, and allergen recognition. J. Biol. Chem. 287, 17459-17470 (2012).

8. McDonnell, J. M. et al. The structure of the IgE Cepsilon2 domain and its role in stabilizing the complex with its high-affinity receptor FcepsilonRIalpha. Nat. Struct. Biol. 8, 437-441 (2001).

9. Galli, S. J., Tsai, M. \& Piliponsky, A. M. The development of allergic inflammation. Nature 454, 445-454 (2008).

10. Kilmon, M. A., Shelburne, A. E., Chan-Li, Y., Holmes, K. L. \& Conrad, D. H. CD23 trimers are preassociated on the cell surface even in the absence of its ligand, IgE. J. Immunol. 172, 1065-1073 (2004).

11. Payet, M. E., Woodward, E. C. \& Conrad, D. H. Humoral response suppression observed with CD23 transgenics. J. Immunol. 163, 217-223 (1999).

12. Palaniyandi, S. et al. Inhibition of CD23-mediated IgE transcytosis suppresses the initiation and development of allergic airway inflammation. Mucosal Immunol. 8, 1262-1274 (2015).

13. Cheng, L. E., Wang, Z.-E. \& Locksley, R. M. Murine B cells regulate serum IgE levels in a CD23-dependent manner. J. Immunol. 185, 5040-5047 (2010).

14. Wurzburg, B. A., Tarchevskaya, S. S. \& Jardetzky, T. S. Structural changes in the lectin domain of CD23, the low-affinity IgE receptor, upon calcium binding. Structure 14, 1049-1058 (2006)

15. Beavil, A. J., Edmeades, R. L., Gould, H. J. \& Sutton, B. J. Alpha-helical coiledcoil stalks in the low-affinity receptor for IgE (Fc epsilon RII/CD23) and related C-type lectins. Proc. Natl Acad. Sci. USA 89, 753-757 (1992).

16. Yu, P., Kosco-Vilbois, M., Richards, M., Köhler, G. \& Lamers, M. C. Negative feedback regulation of IgE synthesis by murine CD23. Nature 369, 753-756 (1994).

17. Busse, W. et al. Omalizumab, anti-IgE recombinant humanized monoclonal antibody, for the treatment of severe allergic asthma. J. Allergy Clin. Immunol. 108, 184-190 (2001).

18. Arm, J. P. et al. Pharmacokinetics, pharmacodynamics and safety of QGE031 (ligelizumab), a novel high-affinity anti-IgE antibody, in atopic subjects. Clin. Exp. Allergy 44, 1371-1385 (2014)

19. Cohen, E. S. et al. A novel IgE-neutralizing antibody for the treatment of severe uncontrolled asthma. MAbs 6, 756-764 (2014).

20. Brightbill, H. D. et al. Antibodies specific for a segment of human membrane IgE deplete IgE-producing B cells in humanized mice. J. Clin. Invest. 120, 2218-2229 (2010)

21. Chu, S. Y. et al. Reduction of total IgE by targeted coengagement of IgE B-cell receptor and $\mathrm{Fc} \gamma \mathrm{RIIb}$ with Fc-engineered antibody. J. Allergy Clin. Immunol. 129, 1102-1115 (2012).

22. Nyborg, A. C. et al. Development of an antibody that neutralizes soluble IgE and eliminates IgE expressing B cells. Cell. Mol. Immunol. 13, 391-400 (2015).

23. Baumann, M. J., Eggel, A., Amstutz, P., Stadler, B. M. \& Vogel, M. DARPins against a functional IgE epitope. Immunol. Lett. 133, 78-84 (2010).

24. Kim, B. et al. Accelerated disassembly of IgE-receptor complexes by a disruptive macromolecular inhibitor. Nature 491, 613-617 (2012).

25. Eggel, A. et al. Accelerated dissociation of IgE-FceRI complexes by disruptive inhibitors actively desensitizes allergic effector cells. J. Allergy Clin. Immunol. 133, 1709-19.e8 (2014)

26. Rinaldi, M. et al. ALX-0962, an anti-IgE Nanobody ${ }^{\circledast}$ with a dual mode of action. Eur. Respir. J. 42, 1765 (2013).

27. Jabs, F. et al. Trapping IgE in a closed conformation by mimicking CD23 binding prevents and disrupts FceRI interaction. Nat. Commun. 9, 7 (2018).

28. Holgate, S. T. \& Polosa, R. Treatment strategies for allergy and asthma. Nat. Rev. Immunol. 8, 218-230 (2008). 
29. Holgate, S. T., Djukanović, R., Casale, T. \& Bousquet, J. Anti-immunoglobulin $\mathrm{E}$ treatment with omalizumab in allergic diseases: an update on antiinflammatory activity and clinical efficacy. Clin. Exp. Allergy 35, 408-416 (2005).

30. Gauvreau, G. M. et al. Efficacy and safety of multiple doses of QGE031 (ligelizumab) versus omalizumab and placebo in inhibiting allergen-induced early asthmatic responses. J. Allergy Clin. Immunol. 138, 1051-1059 (2016).

31. Maurer, M. et al. Ligelizumab for chronic spontaneous urticaria. N. Engl. J. Med. 381, 1321-1332 (2019)

32. Knutti-Müller, J. M., Stadler, B. M., Magnusson, C. M. \& de Weck, L. Human $\mathrm{IgE}$ synthesis in vitro. Detection with monoclonal antibodies. Allergy 41, 457-467 (1986).

33. Wurzburg, B. A. \& Jardetzky, T. S. Conformational flexibility in immunoglobulin E-Fc 3-4 revealed in multiple crystal forms. J. Mol. Biol. 393, 176-190 (2009).

34. Dhaliwal, B. et al. IgE binds asymmetrically to its B cell receptor CD23. Sci. Rep. 7, 45533 (2017).

35. Dhaliwal, B. et al. Crystal structure of IgE bound to its B-cell receptor CD23 reveals a mechanism of reciprocal allosteric inhibition with high affinity receptor Fc RI. Proc. Natl Acad. Sci. USA 109, 12686-12691 (2012).

36. Wurzburg, B. A. et al. An engineered disulfide bond reversibly traps the IgEFc3-4 in a closed, non-receptor binding conformation. J Biol. Chem. 287, 36251-36257 (2012).

37. Greer, A. M. et al. Serum IgE clearance is facilitated by human FceRI internalization. J. Clin. Invest. 124, 1187-1198 (2014).

38. Maurer, D. et al. Fc epsilon receptor I on dendritic cells delivers IgE-bound multivalent antigens into a cathepsin S-dependent pathway of MHC class II presentation. J. Immunol. 161, 2731-2739 (1998).

39. Sallmann, E. et al. High-affinity IgE receptors on dendritic cells exacerbate Th2-dependent inflammation. J. Immunol. 187, 164-171 (2011).

40. Davies, A. M. et al. Allosteric mechanism of action of the therapeutic anti-IgE antibody omalizumab. J. Biol. Chem. 292, 9975-9987 (2017).

41. Pennington, L. F. et al. Structural basis of omalizumab therapy and omalizumab-mediated IgE exchange. Nat. Commun. 7, 11610-11612 (2016).

42. Nakamura, $\mathrm{T}$. et al. In vitro IgE inhibition in B cells by anti-CD23 monoclonal antibodies is functionally dependent on the immunoglobulin $\mathrm{Fc}$ domain. Int. J. Immunopharmacol. 22, 131-141 (2000).

43. Yabuuchi, S., Nakamura, T., Kloetzer, W. S. \& Reff, M. E. Anti-CD23 monoclonal antibody inhibits germline Cepsilon transcription in B cells. Int. Immunopharmacol. 2, 453-461 (2002).

44. Fellmann, M., Buschor, P., Röthlisberger, S., Zellweger, F. \& Vogel, M. High affinity targeting of CD23 inhibits IgE synthesis in human B cells. Immun. Inflamm. Dis. 3, 339-349 (2015).

45. Dombrowicz, D. et al. Anaphylaxis mediated through a humanized high affinity IgE receptor. J. Immunol. 157, 1645-1651 (1996).

46. Gascan, H., Gauchat, J. F., Aversa, G., Van Vlasselaer, P. \& de Vries, J. E. Anti$\mathrm{CD} 40$ monoclonal antibodies or CD4+ T cell clones and IL-4 induce IgG4 and IgE switching in purified human B cells via different signaling pathways. $J$. Immunol. 147, 8-13 (1991).

47. Gould, H. J. \& Sutton, B. J. IgE in allergy and asthma today. Nat. Rev. Immunol. 8, 205-217 (2008).

48. Coyle, A. J. et al. Central role of immunoglobulin (Ig) E in the induction of lung eosinophil infiltration and $\mathrm{T}$ helper 2 cell cytokine production: inhibition by a non-anaphylactogenic anti-IgE antibody. J. Exp. Med. 183, 1303-1310 (1996).

49. Kim, H. L., Leigh, R. \& Becker, A. Omalizumab: practical considerations regarding the risk of anaphylaxis. Allergy Asthma Clin. Immunol. 6, 32 (2010).

50. van Neerven, R. J. et al. Blocking antibodies induced by specific allergy vaccination prevent the activation of $\mathrm{CD} 4+\mathrm{T}$ cells by inhibiting serum-IgEfacilitated allergen presentation. J. Immunol. 163, 2944-2952 (1999).

51. Kabsch, W. XDS. Acta Crystallogr. D Biol. Crystallogr. 66, 125-132 (2010).

52. Adams, P. D. et al. PHENIX: a comprehensive Python-based system for macromolecular structure solution. Acta Crystallogr. D Biol. Crystallogr. 66, 213-221 (2010).

53. Holdom, M. D. et al. Conformational changes in IgE contribute to its uniquely slow dissociation rate from receptor FceRI. Nat. Struct. Mol. Biol. 18, 571-576 (2011).
54. Palakodeti, A. et al. The molecular basis for modulation of human $\mathrm{V} \gamma 9 \mathrm{~V} \delta 2 \mathrm{~T}$ cell responses by CD277/butyrophilin-3 (BTN3A)-specific antibodies. J. Biol. Chem. 287, 32780-32790 (2012).

55. Emsley, P. \& Cowtan, K. Coot: model-building tools for molecular graphics. Acta Crystallogr. D Biol. Crystallogr. 60, 2126-2132 (2004).

56. Zellweger, F. et al. A novel bispecific DARPin targeting Fc $\gamma$ RIIB and FceRIbound IgE inhibits allergic responses. Allergy 72, 1174-1183 (2016)

57. Dhaliwal, B. et al. Crystal structure of IgE bound to its B-cell receptor CD23 reveals a mechanism of reciprocal allosteric inhibition with high affinity receptor FceRI. Proc. Natl Acad. Sci. USA 109, 12686-12691 (2012).

\section{Acknowledgements}

We thank all members of the Eggel and Jardetzky labs involved in this study. We further acknowledge Dr. Mauro Zurini for the preparation and analysis of the anti-IgE antibody fragments, Prof. Jean-Pierre Kinet for providing the transgenic mice expressing the human FceRIa, Bühlmann Laboratories AG for scientific support, Dr. Monique Vogel and Prof. Martin Bachmann for providing cell lines and granting access to equipment, Dr. Paul Engeroff for technical and experimental support and Prof. Peter M. Villiger, and Dr. Reinhold Janocha and Dr. Maximilian Woisetschlaeger for discussions and research support. This research was funded by a grant from the Fondation Acteria (to A.E.), a Swiss National Science Foundation Ambizione grant PZ00P3_148185 (to A.E.), the Research Fund of the Swiss Lung Association, Bern and the Uniscientia foundation (to A.E.), consumable contributions by Novartis AG (to A.E.), and NIH grants AI115469 (to T.S.J.) and HL141493 (to T.S.J. and A.E.).

\section{Author contributions}

C.H., T.S.J. and A.E. conceptualized the study and wrote the manuscript, P.Ga., S.S.T., P. Gu., D.B., R.R., N.Z., S.K. and A.E. performed experiments. All authors contributed to data interpretation and discussion.

\section{Conflict of interest}

C.H. and A.E. are consulting for Novartis Pharma AG. All other authors declare no competing interests.

\section{Additional information}

Supplementary information is available for this paper at https://doi.org/10.1038/s41467019-13815-w.

Correspondence and requests for materials should be addressed to T.S.J. or A.E.

Peer review information Nature Communications thanks Annemiek van Spriel and the other, anonymous, reviewer(s) for their contribution to the peer review of this work. Peer reviewer reports are available.

Reprints and permission information is available at http://www.nature.com/reprints

Publisher's note Springer Nature remains neutral with regard to jurisdictional claims in published maps and institutional affiliations.

Open Access This article is licensed under a Creative Commons Attribution 4.0 International License, which permits use, sharing, adaptation, distribution and reproduction in any medium or format, as long as you give appropriate credit to the original author(s) and the source, provide a link to the Creative Commons license, and indicate if changes were made. The images or other third party material in this article are included in the article's Creative Commons license, unless indicated otherwise in a credit line to the material. If material is not included in the article's Creative Commons license and your intended use is not permitted by statutory regulation or exceeds the permitted use, you will need to obtain permission directly from the copyright holder. To view a copy of this license, visit http://creativecommons.org/ licenses/by/4.0/

(C) The Author(s) 2020 